\title{
Different Fear States Engage Distinct Networks within the Intercalated Cell Clusters of the Amygdala
}

\author{
Daniela Busti, ${ }^{1}$ Raffaella Geracitano, ${ }^{2}$ Nigel Whittle, ${ }^{3}$ Yannis Dalezios,${ }^{4,5}$ Miroslawa Mańko, ${ }^{2}$ Walter Kaufmann, ${ }^{1}$ \\ Kurt Sätzler, ${ }^{6}$ Nicolas Singewald, ${ }^{3}$ Marco Capogna, ${ }^{2}$ and Francesco Ferraguti ${ }^{1}$ \\ ${ }^{1}$ Department of Pharmacology, Innsbruck Medical University, A-6020 Innsbruck, Austria, ${ }^{2}$ Medical Research Council, Anatomical Neuropharmacology \\ Unit, Oxford OX1 3TH, United Kingdom, ${ }^{3}$ Department of Pharmacology and Toxicology, Institute of Pharmacy and Center for Molecular Biosciences \\ Innsbruck, University of Innsbruck, A-6020 Innsbruck, Austria, ${ }^{4}$ Department of Basic Sciences, Faculty of Medicine, University of Crete, Heraklion 71003 , \\ Greece, ${ }^{5}$ Institute of Applied and Computational Mathematics, Foundation for Research and Technology-Hellas, Heraklion 71110, Greece, and ${ }^{6}$ School of \\ Biomedical Sciences, University of Ulster, Coleraine BT52 1SA, County Londonderry, United Kingdom
}

Although extinction-based therapies are among the most effective treatments for anxiety disorders, the neural bases of fear extinction remain still essentially unclear. Recent evidence suggests that the intercalated cell masses of the amygdala (ITCs) are critical structures for fear extinction. However, the neuronal organization of ITCs and how distinct clusters contribute to different fear states are still entirely unknown. Here, by combining whole-cell patch-clamp recordings and biocytin labeling with full anatomical reconstruction of the filled neurons and ultrastructural analysis of their synaptic contacts, we have elucidated the cellular organization and efferent connections of one of the main ITC clusters in mice. Our data showed an unexpected heterogeneity in the axonal pattern of medial paracapsular ITC (Imp) neurons and the presence of three distinct neuronal subtypes. Functionally, we observed that the Imp was preferentially activated during fear expression, whereas extinction training and extinction retrieval activated the main ITC nucleus (IN), as measured by quantifying Zif268 expression. This can be explained by the IPSPs evoked in the IN after Imp stimulation, most likely through the GABAergic monosynaptic innervation of IN neurons by one subtype of Imp cells, namely the medial capsular-projecting (MCp)-Imp neurons. MCp-Imp neurons also target large ITC cells that surround ITC clusters and express the metabotropic glutamate receptor $1 \alpha$. These findings reveal a distinctive participation of ITC clusters to different fear states and the underlying anatomical circuitries, hence shedding new light on ITC networks and providing a novel framework to elucidate their role in fear expression and extinction.

\section{Introduction}

Extinction-based exposure therapies remain the mainstay in the treatment of anxiety disorders, such as phobias and posttraumatic stress disorder, but relapse of maladaptative fear or anxiety is a frequent clinical occurrence (Keane et al., 2006). Elucidation of the neural bases of fear inhibition represents, therefore, the best hope for the identification of novel target mechanisms to

\footnotetext{
Received Nov. 22, 2010; revised Jan. 13, 2011; accepted Feb. 7, 2011.

This work was supported by the Fonds zur Förderung der wissenschaftlichen Forschung Grants S10207 (F.F.) and S10202 (N.S.), the Academic Research Collaboration Programme of the British Council (F.F., M.C.), and the Medical Research Council (M.C.). We thank Michaela Benedet for helping with the processing of recorded slices, Lukas M. Kastlunger for helping with three-dimensional reconstructions, Gabi Schmidt for excellent technical support, L. Klimaschewski (Department of Anatomy, Innsbruck Medical University, Innsbruck, Austria) for helpful advice on the use of the Metamorph software, J. M. Fritschy (Department of Pharmacology and Toxicology, University of Zurich, Zurich, Switzerland) for kindly providing fixed brains from $\mathrm{GABA}_{\mathrm{A}} \alpha 3$-ko mice, and W. Sieghart (Brain Research Centre, Vienna, Austria) and M. Watanabe (Department of Anatomy, Hokkaido University, Sapporo, Japan) for kindly providing the $\mathrm{GABA}_{\mathrm{A}} \alpha 3$ subunit and $\mathrm{mGlu1} \alpha$ receptor antibodies, respectively. We also thank A. Lüthi (Friedrich Miescher Institute, Basel, Switzerland), M. Zoli (University of Modena, Modena, Italy), and R. Tasan, Y. Kasugai, H. Hörtnagel, and G. Sperk (Department of Pharmacology, Innsbruck Medical University) for reading a previous version of this manuscript.

The authors declare no competing financial interests.

Correspondence should be addressed to Francesco Ferraguti, Department of Pharmacology, Innsbruck Medical University, Peter-Mayr Strasse 1a, Innsbruck A-6020, Austria. E-mail: francesco.ferraguti@i-med.ac.at.

DOI:10.1523/JNEUROSCI.6100-10.2011

Copyright $\odot 2011$ the authors $\quad 0270-6474 / 11 / 315131-14 \$ 15.00 / 0$
}

treat anxiety disorders (Davis et al., 2006; Holmes and Quirk, 2010). Over the past years, a number of studies have indicated that fear extinction relies on a complex network of excitatory and inhibitory microcircuits, mainly involving the amygdala, medial prefrontal cortex (mPFC), and hippocampus (Quirk and Mueller, 2008; Ehrlich et al., 2009). Within the amygdala, the basolateral complex (BLA) and the intercalated cell masses (ITCs) appear as two pivotal regions implicated in the acquisition and consolidation of extinction (Paré et al., 2004; Herry et al., 2010). The ITCs, in particular, may represent an important mediator of extinction because they (1) receive information about sensory stimuli from BLA and thalamus (Royer et al., 1999; Vertes and Hoover, 2008), (2) are under control of the mPFC (McDonald et al., 1996; Amano et al., 2010), and (3) give rise to inhibitory projections to the central medial nucleus (CEm) (Paré and Smith, 1993; Royer et al., 1999; Geracitano et al., 2007), the main output area of the amygdala for the expression of conditioned fear responses. Moreover, evidence that activity in ITC clusters is critical for fear extinction was obtained recently with the ablation of ITC neurons located in the intermediate capsule, which resulted in extinction retrieval deficits (Likhtik et al., 2008).

ITCs have been described as densely packed GABAergic neurons surrounding the BLA (Millhouse, 1986; McDonald and Augustine, 1993) and are generally regarded as a functionally 
Table 1. List of primary antibodies used and specification of dilution, source, and specificity

\begin{tabular}{|c|c|c|c|c|c|c|c|}
\hline Antibodies & Antigen & Species & Dilution & Reactions & Source & Characterization of the primary antibody & References \\
\hline$\mu$ opioid receptor & $\begin{array}{l}\text { Synthetic peptide corresponding } \\
\text { to amino acids } 384 \text {-398 pre- } \\
\text { dicted from cloned rat MOR1 }\end{array}$ & Rabbit & 1:20,000 & $a, g$ & $\begin{array}{l}\text { ImmunoStar; catalog \#24216; } \\
\text { lot \#607102 }\end{array}$ & $\begin{array}{l}\text { Preadsorption with MOR peptide ( } 384 \text { - } \\
398 \text { ) at } 10 \mu \mathrm{g} / \mathrm{ml} \text { completely elimi- } \\
\text { nates labeling. The specificity of the } \\
\text { antiserum was determined by immu- } \\
\text { nolabeling of transfected cells, Western } \\
\text { blot analysis, and immunoisolation } \\
\text { studies. }\end{array}$ & Likhtik et al., 2008 \\
\hline Tyrosine hydroxylase & Tyrosine hydroxylase & Rabbit & 1:3000 & b & $\begin{array}{l}\text { Chemicon; catalog \#AB152; lot } \\
\text { \#23060094 }\end{array}$ & $\begin{array}{l}\text { Immunohistochemistry: stains both fresh- } \\
\text { frozen and paraffin-embedded tissue } \\
\text { samples by indirect immunofluores- } \\
\text { cence and immunoperoxidase. Western } \\
\text { blot; immunoprecipitation. It does not } \\
\text { work on paraffin-embedded, human } \\
\text { tissue. }\end{array}$ & $\begin{array}{r}\text { Lode et al., 2000; } \\
\text { Prohaska and } \\
\text { Brokate, } 2001\end{array}$ \\
\hline $\begin{array}{l}\alpha 3 \mathrm{GABA}_{A} \text { receptor } \\
\text { subunit }\end{array}$ & $\begin{array}{l}\text { Amino acidic sequence } 1-11 \text { in } \\
\text { the } \mathrm{N} \text { - terminal domain }\end{array}$ & Rabbit & 1:1500 & c & $\begin{array}{l}\text { Kindly provided by Prof. } \\
\text { Sieghart (Medical University } \\
\text { of Vienna, Vienna, Austria) }\end{array}$ & $\begin{array}{l}\text { Tested immunohistochemically on fixed } \\
\text { brain tissue of both wild-type and } \alpha 3 \\
\text { GABA }_{\mathrm{A}} \text { knock-out mice (kindly pro- } \\
\text { vided by Dr. J. M. Fritschy). }\end{array}$ & Pirker et al., 2003 \\
\hline \multirow[t]{2}{*}{ mGlu1 $\alpha$ receptor } & Amino acidic sequence $945-1127$ & Guinea pig & 1:500 & $f, g, A$ & $\begin{array}{l}\text { Kindly provided by Dr. } \\
\text { Watanabe (Hokkaido Uni- } \\
\text { versity, Sapporo, Japan) }\end{array}$ & $\begin{array}{l}\text { The antibody was tested in mouse by } \\
\text { immunohistochemistry on fixed brain } \\
\text { tissue. }\end{array}$ & $\begin{array}{l}\text { Tanaka and al., 2000; } \\
\text { Ferraguti et al., } \\
2004\end{array}$ \\
\hline & & & 1:1000 & $\mathrm{m}$ & & & \\
\hline FoxP2 & $\begin{array}{l}\text { Synthetic peptide conjugated to } \\
\text { KLH derived from within resi- } \\
\text { dues } 700 \text { to the C terminus of } \\
\text { Himan FOXP2 }\end{array}$ & Rabbit & $1: 2000$ & $d$ & Abcam; catalog \#ab16046 & $\begin{array}{l}\text { Nuclear localization. This antibody gave } \\
\text { positive signal in HEK293 whole-cell } \\
\text { lysate. It reacts with mouse and hu- } \\
\text { man. Not tested in other species. }\end{array}$ & $\begin{array}{l}\text { Campbell et al., 2009; } \\
\text { Enard et al., 2009; } \\
\text { Regad et al., 2009 }\end{array}$ \\
\hline GABA & GABA-BSA & Rabbit & $1: 7000$ & e & Sigma-Aldrich; catalog \#A2052 & $\begin{array}{l}\text { It shows positive binding with GABA and } \\
\text { GABA-KLH in a dot blot assay and } \\
\text { negative binding with BSA. }\end{array}$ & Menegola et al., 2008 \\
\hline $\begin{array}{l}\text { Neurokinin } 1 \\
\text { receptor }\end{array}$ & $\begin{array}{l}\text { Synthetic peptide amino acid } \\
\text { sequence ( } 385-407) \text { of the C } \\
\text { terminus of the rat }\end{array}$ & Rabbit & 1:3000 & $\mathrm{h}$ & $\begin{array}{l}\text { Chemicon; catalog \#AB5060; lot } \\
\text { \#23030368 and } \\
\text { \#0512016863 }\end{array}$ & $\begin{array}{l}\text { Immuhistochemistry: preabsorbtion of the } \\
\text { antiserum with the immunogen pep- } \\
\text { tide eliminates all immunostainings. }\end{array}$ & $\begin{array}{l}\text { Piggins et al., 2001; } \\
\text { Mátyás et al., } 2004\end{array}$ \\
\hline Parvalbumin & Rat muscle parvalbumin & Rabbit & 1:1000 & $\mathrm{i}$ & Swant; catalog \#PV-28; lot \#5.5 & $\begin{array}{l}\text { Western blotting (no cross-reaction was } \\
\text { observed with any other known (a }{ }^{2+} \\
\text { binding proteins). Immunobinding } \\
\text { assay: the title of the serum was in } \\
\text { range of 1:5000 -1:10,000 when } 1 \mathrm{ng} \\
\text { of antigen was applied. }\end{array}$ & Kägi et al., 1987 \\
\hline Parvalbumin & Carp muscle parvalbumin & Mouse & 1:1000 & I & $\begin{array}{l}\text { Sigma; catalog \#P-3171; lot } \\
\quad \text { \#017H4821 }\end{array}$ & $\begin{array}{l}\text { The immunospecificity for parvalbumin } \\
\text { was determined by indirect immuno- } \\
\text { peroxidase staining and immunoblot- } \\
\text { ting. Specific reaction with } \\
\text { parvalbumin of culture nerve cells and } \\
\text { tissue originating from human, mon- } \\
\text { key, rat, mouse, chicken, and fish. }\end{array}$ & $\begin{array}{l}\text { McDonald and Betette, } \\
\text { 2001; Tanahira et } \\
\text { al., } 2009\end{array}$ \\
\hline Calbindin & Rat calbindin D-28k & Rabbit & $1: 10,000$ & $\mathrm{~m}$ & $\begin{array}{l}\text { Swant; catalog \#CB-38a; lot } \\
\quad \# 9.03\end{array}$ & $\begin{array}{l}\text { In immunoblots it recognizes a single } \\
\text { band of } \sim 28 \mathrm{kDa} \text {. Antiserum CB38 } \\
\text { immunolabels a subpopulation of } \\
\text { neurons in the normal brain with high } \\
\text { efficiency but does not stain the brain } \\
\text { of calbindin D- } 28 \text { knock-out mice. }\end{array}$ & Airaksinen et al., 1997 \\
\hline anti-GFP & $\begin{array}{l}\text { Raised against GFP isolated from } \\
\text { Aequorea victoria }\end{array}$ & Rabbit & 1:1000 & $n$ & Invitrogen; catalog \#A11122 & $\begin{array}{l}\text { lgG fraction purified by ion-exchange } \\
\text { chromatography. It is useful for immu- } \\
\text { noprecipitation, immunohistochemis- } \\
\text { try, and Western blotting. }\end{array}$ & $\begin{array}{l}\text { Ausubel et al., 1992; } \\
\quad \text { Conn, } 1999\end{array}$ \\
\hline Egr-1/Zif268 & $\begin{array}{l}\text { Raised against a peptide mapping } \\
\text { at the } C \text { terminus of Egr-1 of } \\
\text { human origin }\end{array}$ & Rabbit & 1:5000 & 0 & $\begin{array}{l}\text { Santa Cruz Biotechnology; } \\
\text { catalog \#sc-189 }\end{array}$ & $\begin{array}{l}\text { It is useful for detection of Egr- } 1 \text { p82 of } \\
\text { mouse, rat, and human origin by West- } \\
\text { ern blotting, immunoprecipitation, } \\
\text { immunofluorescence, and solid-phase } \\
\text { ELISA. }\end{array}$ & $\begin{array}{l}\text { Hefner et al., 2008; } \\
\quad \text { Whittle et al., } 2009\end{array}$ \\
\hline
\end{tabular}

Reactions performed for light microscopy are indicated by small letters, whereas reactions performed for electron microscopy are indicated by capital letters. MOR, $\mu$ opioid receptor; KLH, keyhole limpet hemocyanin; a, b, c, d, e, 0 , Light microscopy, biotinylated anti-rabbit; f, light microscopy, anti-guinea pig Alexa Fluor 488 and Cy3-streptavidin; g, light microscopy, anti-rabbit Cy3, and anti-guinea pig Alexa Fluor 488; $\mathrm{h}$, i, light microscopy, anti-rabbit Alexa Fluor 488 and Cy3-streptavidin; I, light microscopy, anti-mouse Alexa Fluor 488 and Cy3-streptavidin; m, n, light microscopy, anti-rabbit Alexa Fluor 488 and Cy3-streptavidin.

coherent but dispersed bundle of neurons. However, to date, a detailed functional and anatomical characterization of ITCs that takes in consideration their specific connectivity and cytoarchitecture or neurochemistry has not been undertaken. Moreover, the functional homogeneity of ITC clusters has also been challenged by the finding that, in a mouse strain deficient at extin- guishing conditioned fear, the medial paracapsular ITC cluster (Imp) showed a differential pattern of neuronal activation compared with other clusters (Hefner et al., 2008; Whittle et al., 2010). These data raise the question whether distinct ITC clusters, such as the main ITC nucleus (IN), differently participate to fear expression or extinction. Our primarily incomplete knowl- 

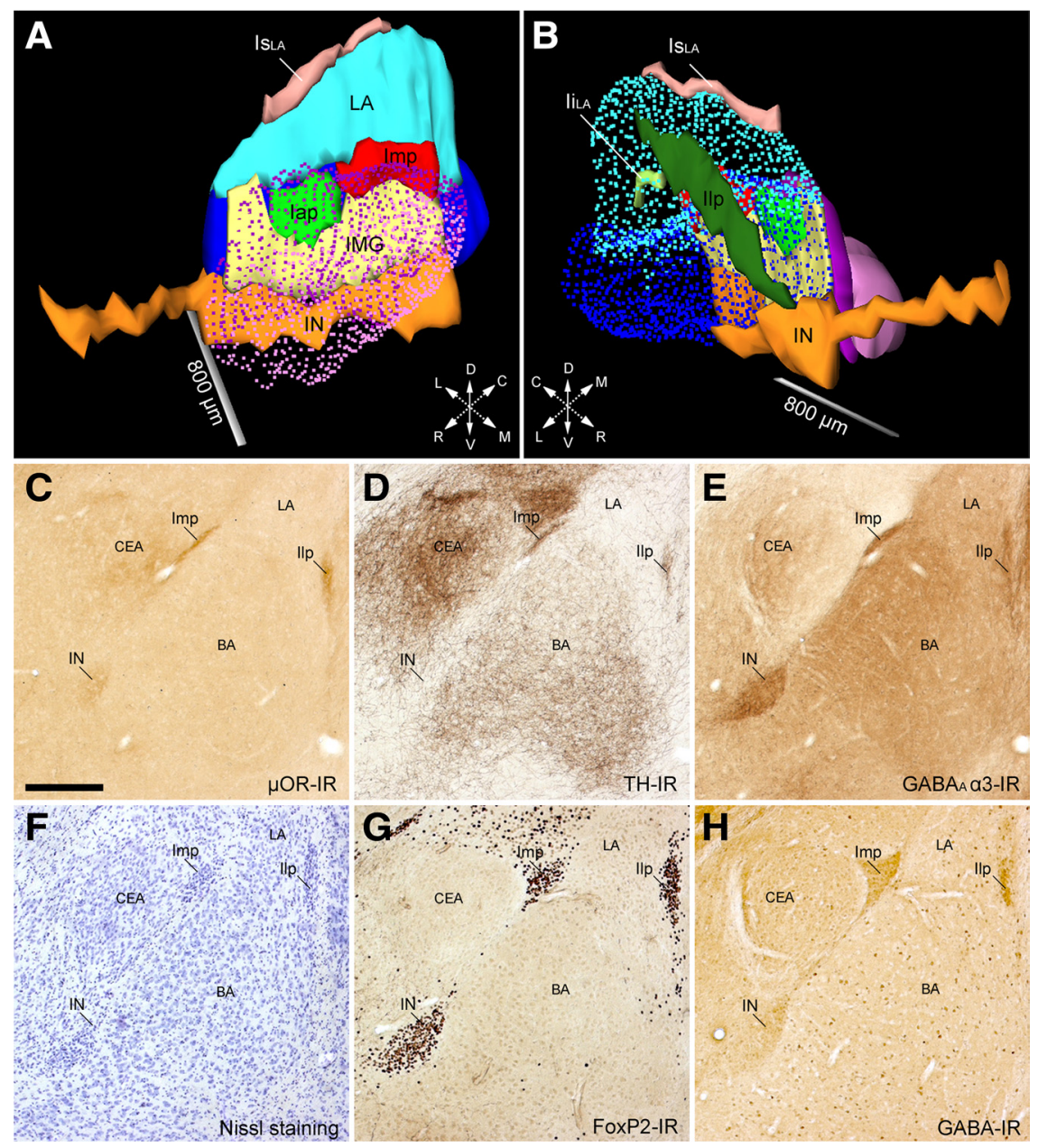

E

BA
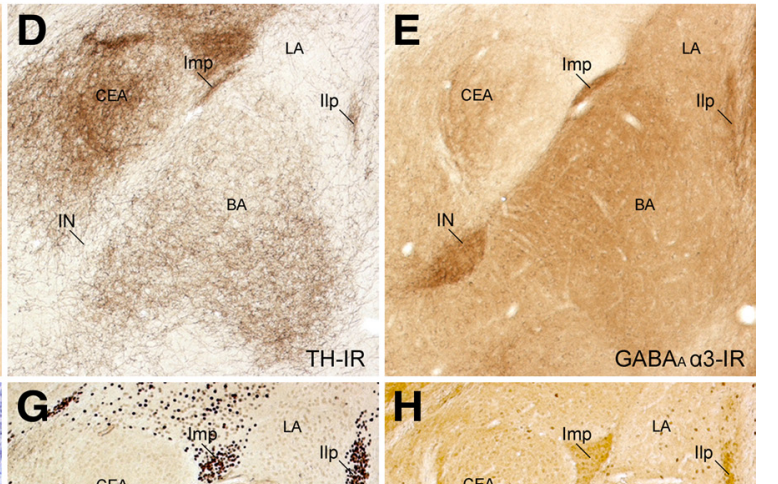
generation of GAD65-GFP mice have been pub-
lished previously (López-Bendito et al., 2004).

Materials and Methods

Animals

All procedures involving animals were performed according to methods approved by the Austrian Animal Experimentation Ethics Board (Bundesministerium für Wissenschaft und Verkehr, Kommission für Tierversuchsangelegenheiten) and the United Kingdom Home Office and were in compliance with the European convention for the protection of vertebrate animals used for experimental and other scientific purposes (ETS number 123). Every effort was taken to minimize animal suffering and the number of animals used. For this study, both C57BL/6N (Charles River) and glutamate decarboxylase 65 (GAD65)-green fluorescent protein (GFP) transgenic mice were used. Details on the

\section{Immunohistochemistry and \\ three-dimensional reconstruction}

Three C57BL/6N adult male mice (25-30 g) were deeply anesthetized by intraperitoneal injection of $0.15 \mathrm{ml} / \mathrm{mouse}$ Thiopental $(50 \mathrm{mg} / \mathrm{ml}$; San$\mathrm{doz}$ ) and perfused with $0.9 \%$ saline for $30 \mathrm{~s}$, followed by ice-chilled fixative made up of $4 \%$ paraformaldehyde w/v (PFA) (Agar Scientific) and $15 \%$ of a saturated picric acid solution $\mathrm{v} / \mathrm{v}$ in phosphate buffer (PB) $(0.1 \mathrm{M}, \mathrm{pH} 7.4)$ for $15 \mathrm{~min}$. Brains were immediately removed from the skull, and tissue blocks containing the amygdala were cut on a Vibratome (VT1000S; Leica Microsystems) in $40-\mu$ m-thick consecutive coronal sections collected in six separate wells. Sections contained in the first well were stained with cresyl violet, whereas all the other slices were processed for immunocytochemistry (for a complete list of antibodies used and reactions, see Table 1) according to the avidin-biotinylated horseradish peroxidase complex (ABC-HRP) (Vector Laboratories) method for free-floating sections as described previously (Kaufmann et al., 2009). For each mouse brain, pictures of the amygdaloid region of both hemispheres were taken with a Carl Zeiss Axioimager M1 light microscope equipped with a Hamamatsu ORCA-ER CCD camera (Hamamatsu) using a $5 \times, 0.16$ numerical aperture (NA) objective and displayed by the Openlab software (version 5.5.0; Improvision). Threedimensional (3D) reconstructions of amygdaloid nuclei and ITC clusters were made using the software OpenCAR (Contour Alignment Reconstruction, version 1.5.7; http://opencar.ulster. ac.uk) as reported previously (Sätzler et al., 2002).

edge of the intrinsic organization of ITCs prevents, at present, a mechanistic explanation of the possible contribution to different fear states of discrete ITC clusters as well as their participation to amygdala microcircuits.

Thus, we sought to elucidate the structural and cellular organization as well as intrinsic connectivity of the Imp in the mouse, by combining whole-cell patch-clamp recordings and biocytin labeling with full anatomical reconstruction and ultrastructural analysis of synaptic contacts. In addition, we have studied whether inhibitory monosynaptic connections exist between clusters within the intermediate capsule and whether distinct ITC clusters display a differential functional activation in fear conditioning, extinction, or retrieval of extinction.
Briefly, images were superimposed, aligned, and adjusted by translation, rotation, and scaling to match the cresyl-violet-stained sections. The borders of nuclei and clusters identified by the immunohistochemical reactions were marked on each section using closed contour lines and interpolated in 3D by tetrahedra using a Delaunay-based reconstruction algorithm based on the estimated average section thickness (Sätzler et al., 2002). The total volume of the ITC clusters and other amygdaloid nuclei has been calculated using the OpenCAR program as the sum of the volumes of all tetrahedra constituting each 3D-reconstructed area.

\section{Acute slice preparation, electrophysiological recordings, and light microscopy analysis of ITC neurons}

Acute coronal slices were prepared from C57BL/6N and GAD65-GFP mice (postnatal days 15-25). Animals were decapitated under isoflurane 
Table 2. Volumetric quantification of the ITC clusters, BLA, and CEA of the mouse amygdala

\begin{tabular}{lllll}
\hline & Left & $n$ & Right & $n$ \\
\hline Volume $\left(\mathrm{mm}^{3}\right.$ ) & & & & \\
Medial paracapsular cluster (Imp) & $0.0098 \pm 0.0026$ & 3 & $0.0084 \pm 0.0020$ & 3 \\
Anterior paracapsular cluster (lap) & $0.0016 \pm 0.0008$ & 3 & $0.0016 \pm 0.0003$ & 3 \\
Main ITC nucleus (IN) & $0.0824 \pm 0.0208$ & 3 & $0.0973 \pm 0.0412$ & 3 \\
Intramedullary gray (IMG) & $0.0142 \pm 0.0017$ & 3 & $0.0165 \pm 0.0016$ & 3 \\
Lateral paracapsular cluster (IIp) & $0.0076 \pm 0.0032$ & 3 & $0.0084 \pm 0.0021$ & 3 \\
Supralateral cluster (IILA) & $0.0042 \pm 0.0013$ & 3 & $0.0041 \pm 0.0012$ & 3 \\
Intralateral cluster (li & $0.0008 \pm 0.0005$ & 3 & $0.0006 \pm 0.0003$ & 3 \\
Basolateral complex of amygdala (BLA) & $0.7296 \pm 0.1086$ & 3 & $0.7854 \pm 0.0566$ & 3 \\
Lateral subdivision of the central nucleus (CEI) & $0.1545 \pm 0.0129$ & 3 & $0.1340 \pm 0.0120$ & 3 \\
Medial subdivision of the central nucleus (CEm) & $0.1488 \pm 0.0118$ & 3 & $0.1315 \pm 0.0097$ & 3 \\
\hline
\end{tabular}

Values represent mean $\pm S D$ and number of analyzed animals $(n)$.

anesthesia (Abbott Laboratories). Brains were rapidly removed and placed in an ice-chilled artificial CSF (ACSF)-sucrose solution containing the following (in mM): 75 sucrose, $87 \mathrm{NaCl}, 2.5 \mathrm{KCl}, 0.5 \mathrm{CaCl}_{2}, 7$ $\mathrm{MgCl}_{2}, 1.25 \mathrm{NaH}_{2} \mathrm{PO}_{4}, 25 \mathrm{NaHCO}_{3}$, and 25 glucose (VWR International), pH 7.3 (saturated with $95 \% \mathrm{O}_{2}, 5 \% \mathrm{CO}_{2}$ ). Slices $(350 \mu \mathrm{m}$ ) were cut on a vibratome (VT 1000S; Leica Microsystems) and transferred to a nylon mesh in a chamber containing the same solution where they were maintained at $37^{\circ} \mathrm{C}$ for $30 \mathrm{~min}$ before returning to room temperature (RT) $\left(24-26^{\circ} \mathrm{C}\right)$ for another $30 \mathrm{~min}$. During this time period, the ACSFsucrose solution was substituted with normal ASCF [containing in mM: $130 \mathrm{NaCl}, 24 \mathrm{NaHCO}_{3}, 3.5 \mathrm{KCl}, 1.25 \mathrm{NaH}_{2} \mathrm{PO}_{4}, 2.5 \mathrm{CaCl}_{2}, 1.5 \mathrm{MgSO}_{4}$, and 10 glucose $\mathrm{pH} 7.3$ (saturated with $95 \% \mathrm{O}_{2}, 5 \% \mathrm{CO}_{2}$ )] at a rate of 4 $\mathrm{ml} / \mathrm{min}$. Acute slices were transferred to a submersion-type recording chamber with temperature control superfused with ACSF (rate of 1-2 $\mathrm{ml} / \mathrm{min}$ ) and visualized with a $10 \times, 0.3 \mathrm{NA}$ or a $40 \times, 0.8 \mathrm{NA}$ (Carl Zeiss) water-immersion objective coupled with infrared and differential interference contrast optics linked to a video camera (Newvicon C2400; Hamamatsu). Somatic whole-cell patch-clamp recordings were performed from visually identified cells using borosilicate glass capillaries (GC120F, 1.2 mm outer diameter, 4-6 M ; Clarke Electromedical Instruments), pulled on a DMZ puller (Zeitz-Instrumente $\mathrm{GmbH}$ ), and filled with a filtered intracellular solution consisting of $126 \mathrm{~mm}$ potassium gluconate, $4 \mathrm{~mm} \mathrm{KCl}, 4 \mathrm{~mm} \mathrm{Mg}-\mathrm{ATP}, 0.3 \mathrm{~mm} \mathrm{Na}-\mathrm{GTP}, 10 \mathrm{~mm}$ $\mathrm{Na}_{2}$-phosphocreatine, $10 \mathrm{~mm}$ HEPES, and $0.5 \% \mathrm{w} / \mathrm{v}$ biocytin (all from Sigma-Aldrich), osmolarity of 270-280 mOsm/L without biocytin, pH 7.3 with $\mathrm{KOH}$. IPSCs were evoked after extracellular monopolar stimulation using a patch pipette filled with ACSF, in the presence of kynurenic acid (3 mm; SigmaAldrich). The IPSCs were evoked at a holding potential of $-65 \mathrm{mV}$ and had a reversal potential of $-90.4 \mathrm{mV}$. An input-output protocol was performed (range used, $5-50 \mu \mathrm{A}$, step of 5 $\mu \mathrm{A})$. The kinetic data refer to responses evoked by "minimal stimulation" intensity. All electrophysiological signals were amplified (10 $\mathrm{mV} / \mathrm{pA}$; EPC9/2 amplifier; Pulse software; Heka), filtered at $2.9 \mathrm{kHz}$, and digitized at 5 or $10 \mathrm{kHz}$. Data analysis of the membrane passive and active responses was performed as described previously (Geracitano et al., 2007). The evoked IPSC peak amplitude (in picoamperes), latency (in milliseconds), $20-80 \%$ rise time (in milliseconds), and decay time (in milliseconds) were analyzed with a user-defined program in IGOR.

After electrophysiological recording, slices were immersed in a fixative solution, containing $4 \%$ PFA w/v, $15 \%$ of a saturated picric acid solution $\mathrm{v} / \mathrm{v}$ and $0.05 \%$ glutaraldehyde $\mathrm{v} / \mathrm{v}$ in $\mathrm{PB}$, for $\sim 24 \mathrm{~h}$ at $4^{\circ} \mathrm{C}$. Slices were then embedded in a block of $10 \%$ gelatin in

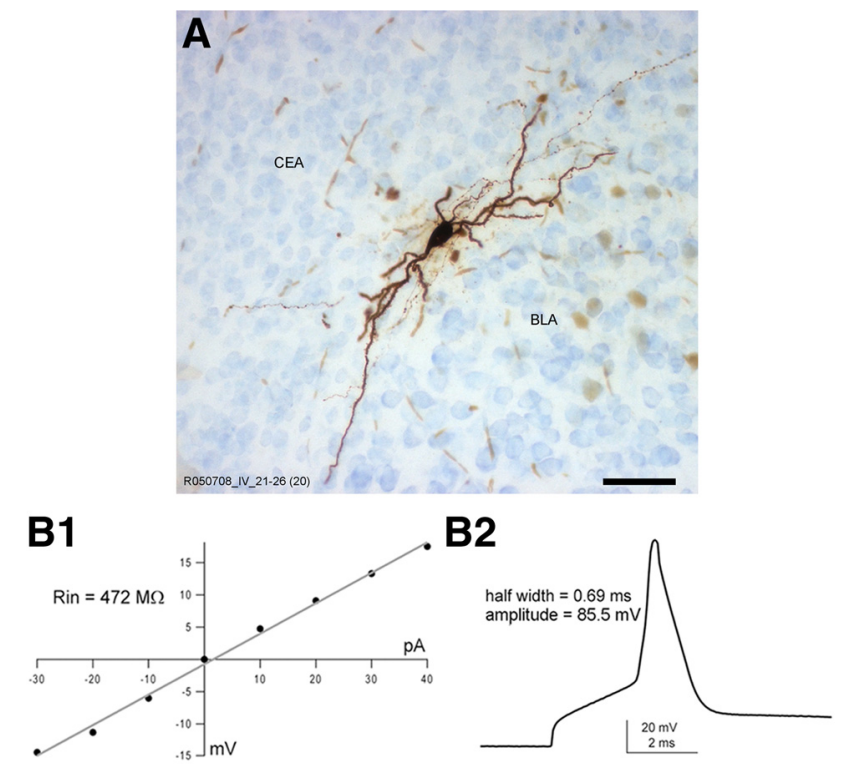

B3

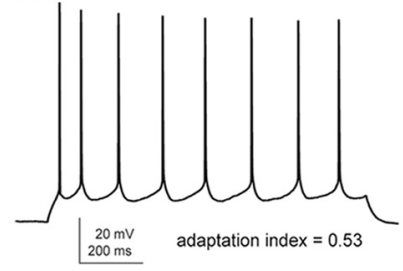

B4

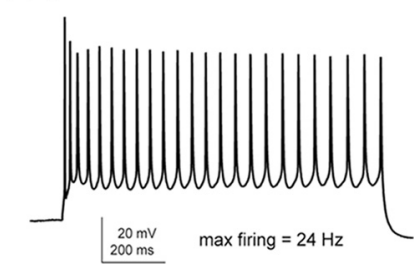

Figure 2. Morphological features and electrophysiological responses of representative Imp neurons. $A$, Light microscopy image of a representative biocytin-filled in vitro recorded Imp neuron showing its typical bipolar structure. $\boldsymbol{B}_{1}$, Input resistance of a typical Imp neuron [R013106 1-36 (\#7 in cluster analysis dendrogram)] measured referring to the $I-V$ plot. $\boldsymbol{B}_{\mathbf{2}^{\prime}}$ Representative action potential of moderate width evoked by a depolarizing current pulse $(1000 \mathrm{pA} \mathrm{for} 3 \mathrm{~s})$ and used to determine the action potential half-width and amplitude. $\boldsymbol{B}_{3}$, The adaptation index was estimated on the bases of the sustained firing pattern obtained in response to a longer current stimulus ( $50 \mathrm{pA}$ for $1 \mathrm{~s}$ ). $\boldsymbol{B}_{\mathbf{}^{\prime}}$, A stronger depolarizing current pulse (150 pA for $1 \mathrm{~s}$ ) was elicited to calculate the maximal firing rate. Scale bar, $50 \mu \mathrm{m}$.
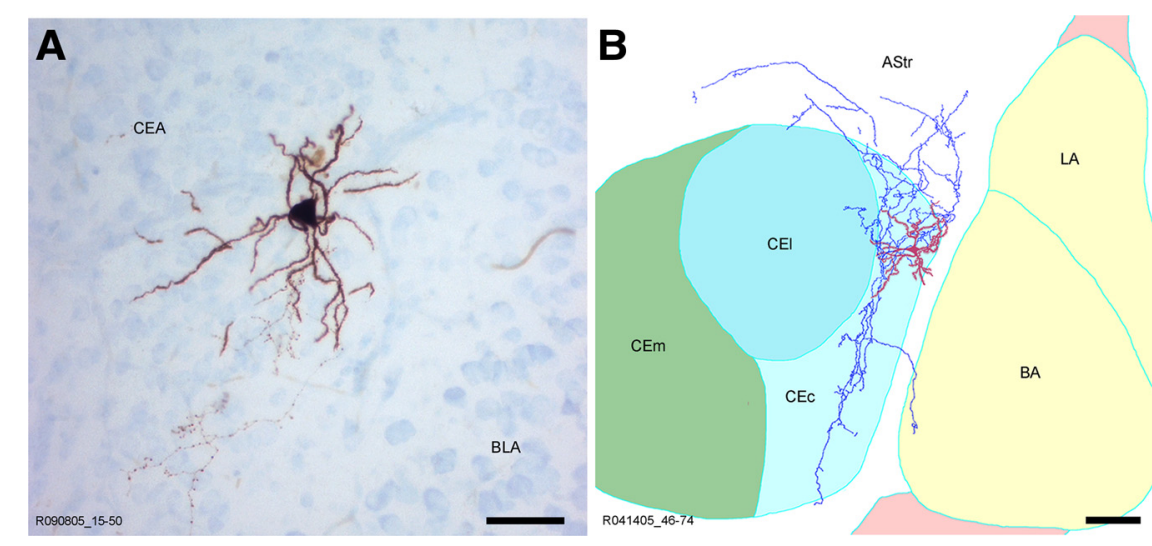

Figure 3. Morphological features and axonal pattern of a representative CEc neuron. $A, B$, Light microscopy micrograph $(\boldsymbol{A})$ and reconstruction by camera lucida $(\boldsymbol{B})$ of a representative in vitro recorded and biocytin-filled $(\mathrm{E}$ c neuron. The soma and dendrites are labeled in red, whereas the axon is marked in blue. The boundaries of the amygdaloid subregions have been drawn referring to the section containing the soma. AStr, Amygdalostriatal transition area; LA, lateral nucleus of amygdala. Scale bars: $\boldsymbol{A}, 50 \mu \mathrm{m} ; \boldsymbol{B}, 100 \mu \mathrm{m}$. later processed for immunofluorescence according to previously published procedures (Ferraguti et al., 2004). Briefly, after resectioning, sections were cryoprotected overnight with $20 \%$ sucrose (Merck KGaA) in 
Table 3. Morphological and physiological properties of CEc and Imp neurons

\begin{tabular}{|c|c|c|c|c|c|}
\hline Parameter & CEC & $n$ & Imp & $n$ & $p$ value \\
\hline \multicolumn{6}{|l|}{ Morphological properties } \\
\hline Soma maximal diameter ( $\mu \mathrm{m})$ & $19.8 \pm 0.8$ & 12 & $18.4 \pm 1.9$ & 22 & $p=0.32$ ( $t$ test $)$ \\
\hline Soma minimal diameter $(\mu \mathrm{m})$ & $14 \pm 1.2$ & 11 & $11.8 \pm 0.5$ & 24 & $p=0.60$ ( $t$ test $)$ \\
\hline Soma volume $\left(\mu \mathrm{m}^{3}\right)$ & $2997 \pm 456$ & 11 & $2345 \pm 377$ & 22 & $p=0.07$ (M-W test) \\
\hline \multicolumn{6}{|l|}{ Passive membrane properties } \\
\hline$R_{\text {in }}(\mathrm{M} \Omega)$ & $270 \pm 19$ & 7 & $600 \pm 52$ & 31 & $p=0.0003$ (M-W test) \\
\hline Membrane $\tau$ (ms) & $22 \pm 2.4$ & 7 & $27.2 \pm 1.8$ & 31 & $p=0.349$ (M-W test) \\
\hline$C_{m}(n F)$ & $0.083 \pm 0.0071$ & 7 & $0.062 \pm 0.0013$ & 31 & $p=0.008(\mathrm{M}-\mathrm{W}$ test $)$ \\
\hline Sag ratio & $0.83 \pm 0.10$ & 7 & $0.91 \pm 0.012$ & 27 & $p=0.931$ (M-W test) \\
\hline \multicolumn{6}{|l|}{ Active membrane properties } \\
\hline $\mathrm{AHP}(\mathrm{mV})$ & $-16 \pm 2.1$ & 7 & $-11 \pm 0.64$ & 31 & $p=0.009$ ( $t$ test $)$ \\
\hline AP amplitude (mV) & $82 \pm 3.3$ & 7 & $78 \pm 1.6$ & 31 & $p=0.301$ ( $t$ test $)$ \\
\hline AP width (ms) & $0.60 \pm 0.097$ & 7 & $0.84 \pm 0.039$ & 31 & $p=0.015(t$ test $)$ \\
\hline Adaptation index & $0.52 \pm 0.050$ & 7 & $0.56 \pm 0.045$ & 27 & $p=0.551$ (M-W test $)$ \\
\hline Max firing $(\mathrm{Hz})$ & $25 \pm 4.4$ & 7 & $28 \pm 2.7$ & 27 & $p=0.651(t$ test $)$ \\
\hline
\end{tabular}

AHP, Afterhyperpolarization; AP, action potential. Values represent the mean \pm SEM. Normally distributed (Shapiro-Wilk test) data were analyzed using the unpaired Student's $t$ test, whereas all other data were analyzed using the nonparametric Mann-Whitney test.

$0.1 \mathrm{~m} \mathrm{~PB}$, rapidly frozen in liquid $\mathrm{N}_{2}$, and thawed with $0.1 \mathrm{M} \mathrm{PB}$ at room temperature, repeated twice. Sections were then incubated free floating for $1 \mathrm{~h}$ at RT in a blocking solution containing 20\% normal serum (NS) in Tris-buffered saline (TBS) $(0.9 \% \mathrm{NaCl}, \mathrm{pH} 7.4)$ and, afterward, for $48 \mathrm{~h}$ at $4^{\circ} \mathrm{C}$ with primary antibodies (Table 1 ) diluted in TBS plus $1 \%$ NS. After several washes in TBS, sections were incubated with appropriate secondary antibodies conjugated to Alexa Fluor 488 (1:1000; Invitrogen) and, to visualize the biocytin, with streptavidin-cyanine 3 (Cy3) (1:1000; Vector Laboratories). Sections were mounted on slides in Vectashield (Vector Laboratories) and examined using a Carl Zeiss Axioimager M1 microscope equipped with epifluorescence illumination. Images were recorded through a Hamamatsu ORCA-ER CCD camera (Hamamatsu) and analyzed and displayed using the Openlab software (Improvision). Brightness and contrast were adjusted for the whole frame, without changing any specific features within.

After immunofluorescence analysis, sections were extensively washed in TBS, and filled neurons were then revealed by the ABC-HRP reaction as described previously (Geracitano et al., 2007). Some recorded and filled neurons were further processed for electron microscopy (see below), whereas others were counterstained with $0.5 \%$ cresyl violet acetate (Sigma). Camera lucida reconstruction of confirmed ITC neurons was performed using a drawing tube mounted onto a Carl Zeiss Axioplan2 microscope with a $40 \times, 0.8$ NA objective.

To calculate the volume of neuronal somata (considered as spheroids), we used the following formula: $V=\left(4 / 3 \pi \times \max ^{2} \times \min \right)$, in which max is the maximal radius and min the minimal radius.

Pre-embedding electron microscopy of recorded and filled neurons Some recorded slices were processed for electron microscopy as mentioned above. After revealing the biocytin by ABC-HRP reaction, contrast was enhanced using $2 \%$ osmium tetroxide v/v (Agar Scientific) in $0.1 \mathrm{M} \mathrm{PB}$ for $40 \mathrm{~min}$ at RT and 1\% uranyl acetate w/v (Agar Scientific) in $50 \%$ ethanol for $30 \mathrm{~min}$ at RT. The sections were then dehydrated in increasing gradients of ethanol, immersed in propylene oxide, and embedded in epoxy resin (Durcupan ACM; Sigma-Aldrich) on greased glass slides. Regions of interest were dissected under a stereomicroscope and reembedded in Durcupan ACM. Serial ultrathin sections $(70 \mathrm{~nm})$ were cut with an ultramicrotome (Ultracut S; Leica Microsystems) and collected on Formvar-coated copper slot grids. The ultrastructural analysis of the specimens was performed using a Philips CM 120 electron microscope equipped with a Morada CCD TEM camera (Soft Imaging Systems).

Fear conditioning and immediate-early gene expression

Adult male C57BL/6N mice (12-16 weeks) were housed (four to five per cage) side-by-side under controlled temperature $\left(22 \pm 2^{\circ} \mathrm{C}\right)$ and humidity $(50-60 \%)$ on a $12 \mathrm{~h}$ light/dark cycle (lights on, 7:00 A.M.).

Experiment 1: ITC neural activation patterns after fear expression and fear extinction. Fear conditioning and extinction was performed as de- scribed previously (Hefner et al., 2008). Mice were fear conditioned in a $26 \times 30 \times 32 \mathrm{~cm}$ chamber with transparent walls and a metal rod floor (context A). After a $120 \mathrm{~s}$ acclimation period, an $80 \mathrm{~dB}$ white noise [conditioned stimulus (CS)] lasting $30 \mathrm{~s}$ was paired in the last $2 \mathrm{~s}$ with a $0.6 \mathrm{~mA}$ scrambled footshock [unconditioned stimulus (US)] three times (120 s interpairing interval). Mice were returned to the home cage after a $120 \mathrm{~s}$ no-stimulus consolidation period after the final pairing. Twentyfour hours later, groups of mice were subjected to either fear expression (one CS presentation; $n=6$ ) or fear extinction (15 CS presentations; $n=$ 6) in a novel context (context B) $(26 \times 20 \times 13 \mathrm{~cm}$ cage, cleaned with a $100 \%$ ethanol, illuminated to $10 \mathrm{lux}$ ). After a $120 \mathrm{~s}$ acclimation period, mice were subjected to fear expression or fear extinction as described above ( $5 \mathrm{~s}$ no-stimulus interval). Mice were returned to the home cage after a $120 \mathrm{~s}$ no-stimulus consolidation period. To provide an immediate-early gene control group, mice $(n=4)$ were subjected to the same conditioning and extinction procedures as the fear expression group with the exception that there was no US during conditioning. Freezing was measured as an index of fear (Blanchard and Blanchard, 1969), manually scored based on DVD recordings of the duration of the CS (120 s), defined as no visible movement except that required for respiration, and converted to a percentage [(duration of freezing within the CS/total time of the CS) $\times 100$ ] by a trained observer blind to the animal treatment.

Experiment 2: ITC neural activation pattern after extinction retrieval. In these experiments, we used a slightly stronger conditioning protocol to obtain greater fear expression (Hefner et al., 2008) and thus a pronounced difference in between-session extinction. Mice were subjected to a similar fear conditioning protocol as described above, in which however the number of pairings was increased from three to five and the footshock intensity from 0.6 to $0.7 \mathrm{~mA}$. Also, the duration of the CS was increased (from 30 to $120 \mathrm{~s}$ ). Twenty-four hours after $15 \mathrm{CS}$ extinction training, extinction retrieval was tested in context B. After a $120 \mathrm{~s}$ acclimation period, mice received one CS presentation, followed by a $120 \mathrm{~s}$ no-stimulus consolidation period before the mice were returned to the home cage.

Immediate-early gene quantification. Mice were killed $2 \mathrm{~h}$ after the start of the fear expression, fear extinction, and extinction retrieval sessions in accordance with previous studies (Hefner et al., 2008). Mice were deeply anesthetized with an overdose of sodium pentobarbital $(200 \mathrm{mg} / \mathrm{kg})$ and transcardially perfused with $20 \mathrm{ml}$ of $0.9 \%$ saline, followed by $20 \mathrm{ml}$ of $4 \%$ PFA w/v in $0.1 \mathrm{~mol} / \mathrm{L} \mathrm{PB}, \mathrm{pH} 7.4$. Brains were then removed, postfixed at $4^{\circ} \mathrm{C}$ overnight in the same fixative, and sectioned in the coronal plane at $40 \mu \mathrm{m}$ thickness on a vibratome (VT1000S; Leica Microsystems). Free-floating sections were processed for Zif268 immunoreactivity (IR) as described previously (Hefner et al., 2008). The number of Zif268-positive neurons in ITCs was quantified at bregma $-1.58 \mathrm{~mm}$. 
A

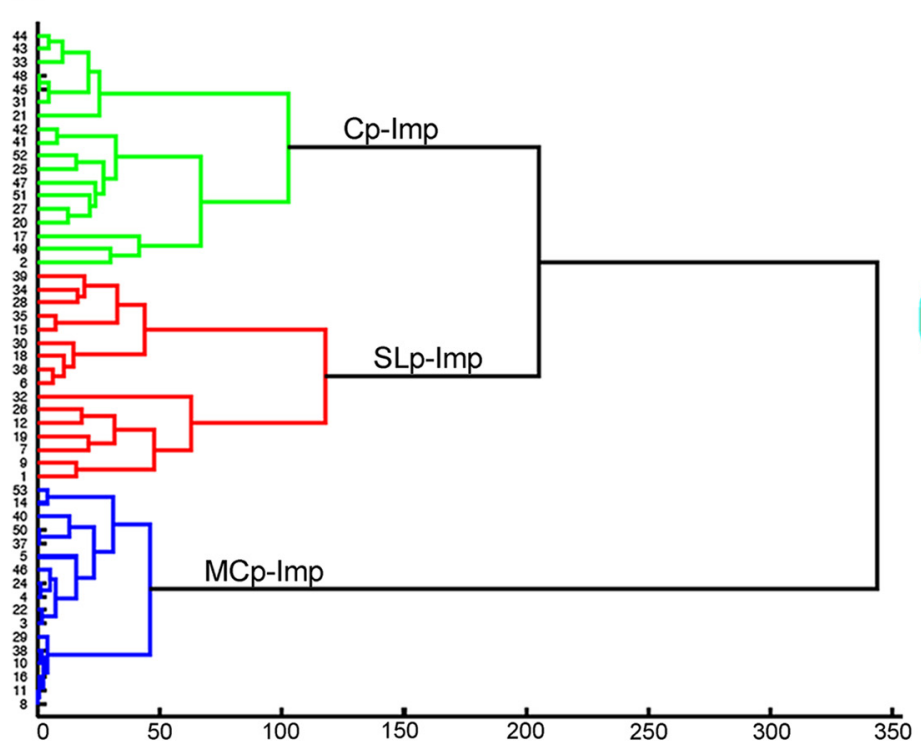

C

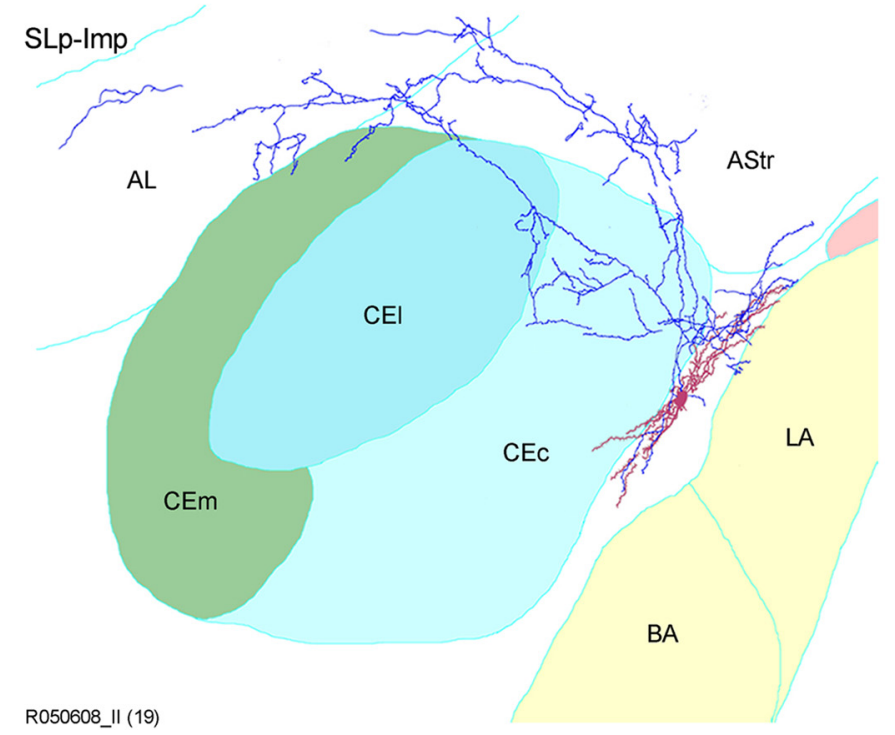

B

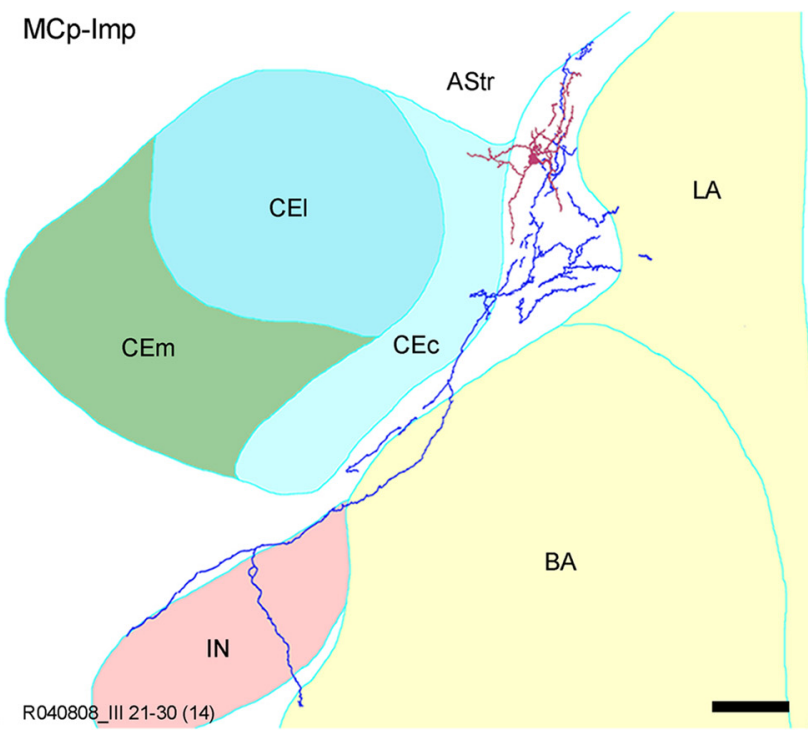

D

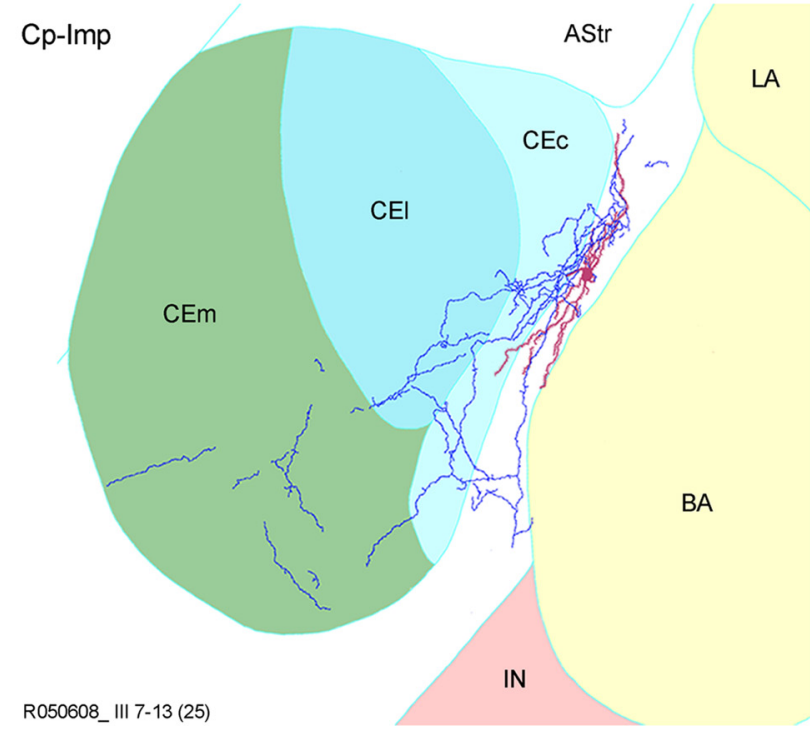

Figure 4. Unsupervised cluster analysis identifies three subclasses of Imp neurons. $\boldsymbol{A}$, The dendrogram illustrates the clustering applied to the sample of 51 Imp neurons. The $y$-axis represents individual cells, and the $x$-axis represents the average Euclidian within-cluster linkage distance. Imp neurons were clustered into three subclasses: MCp-Imp neurons ( $n=17)$, in blue; SLp-Imp neurons $(n=16)$, in red; and $(p-I m p$ neurons $(n=18)$ in green. Representative reconstructions of the following: $\boldsymbol{B}$, an MCp-Imp neuron, showing a major axonal branch traveling along the intermediate capsule to reach the IN; C, SLp-Imp neuron, characterized by a primary axon running alongside the dorsal border of the CEA and reaching the AL; $\boldsymbol{D}$, Cp-Imp neuron whose axon extensively innervates the CEc and, as in this case, the CEm. In all the reconstructions, soma and dendrites are drawn in red, and the axonal arborization is shown in blue. Delineation of the anatomical boundaries of the different amygdaloid nuclei was drawn on the section containing the soma. AStr, Amygdalostriatal transition area; LA, lateral nucleus of amygdala. Scale bar, $100 \mu \mathrm{m}$.

\section{Statistical analysis}

Data are expressed as mean \pm SEM. When data were distributed normally (Shapiro-Wilk test), statistical differences between groups were determined using unpaired Student's $t$ test or ANOVA as appropriate. Alternatively, nonparametric tests were used as indicated. All behavioral data were analyzed using ANOVA, with repeated measures for CS when required, followed by Bonferroni's post hoc analysis. Zif268 expression was analyzed using ANOVA, followed by Bonferroni's post hoc analysis. Differences were considered to be significant at $p<0.05$.

\section{Cluster analysis}

For each reconstructed ITC neuron, the total amount of axon present in the intermediate capsule, paracapsular and lateral (CEc/l) and CEm subdivisions of the central nucleus of the amygdala (CEA), BLA, and ansa lenticularis (AL) has been calculated by the image analysis software MethaMorph (Methamorph Offline, version 7.5.6.0; MDS Analytical Technologies). The indicated bregma position of ITC neurons is referred to the section containing the major portion of the soma and evaluated compared with the mouse brain atlas of Paxinos and Franklin (2001). For cluster analysis, we used the Euclidean distance followed by the minimum variance ward algorithm embedded in Matlab (MathWorks). The lowest $(>1)$ number of final clusters was determined as the one that provided a robust inconsistency coefficient value. The same procedure applied on random samples of data did not result in the allocation of ITC neurons in different clusters (i.e., the same neurons remained grouped together, independently of the sample size). 
Table 4. Morphological parameters of Imp neurons

\begin{tabular}{|c|c|c|c|c|c|c|}
\hline & MCp-Imp & $n$ & SLp-Imp & $n$ & Cp-Imp & $n$ \\
\hline Soma maximal diameter ( $\mu \mathrm{m})$ & $20.2 \pm 1.4$ & 11 & $18.9 \pm 1.01$ & 5 & $14.7 \pm 0.75$ & 5 \\
\hline Soma minimal diameter ( $\mu \mathrm{m})$ & $12.4 \pm 0.9$ & 11 & $12.1 \pm 0.8$ & 7 & $10.2 \pm 0.6$ & 5 \\
\hline Soma volume $\left(\mu \mathrm{m}^{3}\right)$ & $3052 \pm 673$ & 11 & $2220 \pm 278$ & 5 & $1153 \pm 81.4$ & 6 \\
\hline Total axon length ( $\mu \mathrm{m})$ & $2483.1 \pm 312.5$ & 17 & $4042 \pm 701.7$ & 16 & $3503.4 \pm 595.7$ & 18 \\
\hline Mean $\%$ of axon in internal capsules & $89.7 \pm 2.02$ & 17 & $46.1 \pm 3.8$ & 16 & $19.7 \pm 2.3$ & 18 \\
\hline Mean \% of axon in CEI & $4.3 \pm 1$ & 17 & $25.3 \pm 3.6$ & 16 & $65.2 \pm 4.3$ & 18 \\
\hline Mean \% of axon in CEm & $0.3 \pm 0.32$ & 17 & $1.8 \pm 1$ & 16 & $3.6 \pm 1.4$ & 18 \\
\hline Mean $\%$ of axon in BLA & $4 \pm 1.2$ & 17 & $3 \pm 1.21$ & 16 & $2.2 \pm 1.2$ & 18 \\
\hline Mean $\%$ of axon in $\mathrm{AL}$ & 0 & 17 & $6.8 \pm 3.3$ & 16 & $2.7 \pm 1.6$ & 18 \\
\hline Mean \% of axon in BSTIA & $1.6 \pm 1.03$ & 17 & $0.4 \pm 0.4$ & 16 & $3.0 \pm 1.3$ & 18 \\
\hline Mean \% of axon in AStr & $0.1 \pm 0.1$ & 17 & $16.5 \pm 3.6$ & 16 & $3.7 \pm 2.1$ & 18 \\
\hline
\end{tabular}

Values represent the mean \pm SEM. BSTIA, Bed nucleus of the stria terminalis intra-amygdaloid division; AStr, amygdalostriatal transition area.

\section{Results}

The mouse amygdala contains distinct ITC clusters

Despite the fact that several studies have reported the spatial distribution of ITCs in both rat and mouse (Alheid et al., 1995; Marowsky et al., 2005), no systematic analysis to date has tried to recognize their different components/clusters. We thus used several different histochemical and immunocytochemical stains (Table 1) to reveal the boundaries of ITCs and other neighboring amygdaloid regions (Fig. 1) in serial sections of adult mouse brains $(\mathrm{C} 57 \mathrm{BL} / 6 \mathrm{~N})$. 3D reconstruction of the ITCs allowed the identification of six apparently separated clusters and of an area previously known as intramedullary gray (IMG), corresponding to part of the intermediate capsule interposed between the Imp and IN (Fig. 1A, $B$, Table 2). As shown in Figure 1, all identified ITC clusters displayed $\mu$ opioid receptor ( $\mu \mathrm{OR}$ ) (Fig. 1C) (Likhtik et al., 2008), GABA ${ }_{\mathrm{A}}$ receptor $\alpha 3$ subunit (Fig. $1 E$ ) (Marowsky et al., 2004), and FoxP2 (Fig. 1G) (Kaoru et al., 2010) IR as well as intense labeling for GABA (Fig. $1 H$ ). Conversely, IR for tyrosine hydroxylase (TH) appeared highly dishomogeneous with the caudal part of the IN nearly lacking labeling for TH (Fig. $1 D)$. The IMG contained few scattered neurons displaying the same staining pattern of other ITC clusters.

Our volume measurement of the BLA $\left(0.758 \pm 0.039 \mathrm{~mm}^{3}\right)$ was consistent with a previous study (von Bohlen und Halbach and Unsicker, 2002), and, as expected, we found small volume variability of distinct ITC clusters and other amygdaloid nuclei among three genetically identical C57BL6/N mouse brains (Table 2). On the whole, the ITC clusters were found to take up a total volume of $0.129 \pm 0.012 \mathrm{~mm}^{3}$, thus representing $\sim 17 \%$ of the BLA and $\sim 45 \%$ of the CEA.

\section{ITC neurons have heterogeneous axonal projections and differ from CEc neurons}

To establish whether all ITC neurons within the Imp cluster have similar extrinsic connectivity, morphological properties, and electrophysiological responses, patch-clamp recordings and filling with biocytin were performed from the somata of 160 neurons presumed to be within the intermediate capsule. Of these cells, we recovered 107 neurons, and, after precise anatomical localization, 69 were confirmed as ITC neurons with the soma in the Imp, anterior paracapsular cluster (Iap), or IMG. Of the remaining filled and recorded neurons, 21 were positioned in the $\mathrm{CEc}$ and 13 in the BLA, and four were located in the amygdalastriatum transition zone. All filled ITC neurons were medium spiny and displayed the characteristic bipolar shape with primary dendrites oriented parallel to the main axis of the intermediate capsule (Fig. 2A). Several electrophysiological responses of the recorded ITC cells were elicited to study their passive and active
Table 5. Passive and active membrane properties of Imp neurons

\begin{tabular}{lcccccr}
\hline Parameter & MCp-Imp & $n$ & SLp-Imp & $n$ & Cp-Imp & $n$ \\
\hline Passive membrane & & & & & & \\
$\quad$ properties & & & & & & \\
$R_{\text {in }}(\mathrm{M} \Omega$ ) & $705 \pm 116$ & 11 & $605 \pm 67$ & 10 & $449 \pm 72$ & 8 \\
Membrane $\tau(\mathrm{ms})$ & $21.65 \pm 1.44$ & 11 & $26.47 \pm 2.36$ & 10 & $36.24 \pm 4.42$ & 8 \\
$C_{\mathrm{m}}$ (nF) & $0.038 \pm 0.006$ & 11 & $0.048 \pm 0.006$ & 10 & $0.121 \pm 0.046$ & 8 \\
Sag ratio & $0.92 \pm 0.01$ & 11 & $0.91 \pm 0.03$ & 8 & $0.95 \pm 0.01$ & 6 \\
EPD & $26.04 \pm 2.64$ & 10 & $26.00 \pm 2.03$ & 10 & $35.01 \pm 3.44$ & 7 \\
Active membrane & & & & & & \\
$\quad$ properties & & & & & & \\
AHP (mV) & $-9.47 \pm 1.86$ & 12 & $-11.12 \pm 0.92$ & 10 & $-13.29 \pm 1.91$ & 7 \\
AP amplitude (mV) & $82.33 \pm 6.07$ & 12 & $75.94 \pm 2.83$ & 10 & $82.94 \pm 2.99$ & 7 \\
AP width (ms) & $0.80 \pm 0.06$ & 12 & $0.85 \pm 0.08$ & 10 & $0.88 \pm 0.09$ & 7 \\
Adaptation index & $0.61 \pm 0.08$ & 10 & $0.58 \pm 0.07$ & 8 & $0.51 \pm 0.09$ & 7 \\
Max firing (Hz) & $33.8 \pm 5.1$ & 10 & $21.9 \pm 3.8$ & 8 & $27.4 \pm 4.3$ & 7 \\
\hline
\end{tabular}

EPD, Early postdenervation depolarization; AHP, afterhyperpolarization; AP, action potential. Values represent mean \pm SEM and number of recordings $(n)$.

membrane properties. Consistent with our previous report (Geracitano et al., 2007), these neurons exhibited relatively high input resistance $(>400 \mathrm{M} \Omega)$, maximal firing frequency up to $30 \mathrm{~Hz}$ with limited adaptation, and moderate action potential width (Fig. 2B). Given the spatial contiguity and common subpallial origin of Imp neurons and neurons with the soma located in the CEc (Waclaw et al., 2010), we next examined whether the latter cells could be erroneously identified as ITC neurons. CEc neurons were mostly $(>80 \%)$ multipolar with densely spiny dendrites, shorter than those of Imp neurons and primarily confined within the CEc subdivision. Their axons were also mainly contained within the boundaries of this nuclear subdivision (Fig. $3 A, B)$, although some branches could be seen entering the intermediate and lateral subdivisions of the CEA or to leave the nucleus either ventrally or dorsally. When comparing the physiological properties, Imp neurons showed a significantly higher input resistance $(p<0.01$, Mann-Whitney test) and lower membrane capacitance ( $p<0.01$, Mann-Whitney test), whereas all other measured passive membrane properties were similar (Table 3). The lower input resistance measured for CEc cells might be explained by a larger soma, but no significant differences were detected in the cell maximal and minimal diameter nor in the volume of CEc compared with Imp neurons (Table 3 ). Imp neurons also showed longer spike duration $(p<0.05$, unpaired $t$ test $)$ and a less negative afterhyperpolarization $(p<0.01$, unpaired $t$ test) than CEc cells. Both the anatomical and the physiological features obtained in mice are consistent with previous descriptions of CEc/l neurons in other species (Royer et al., 1999; Chieng et al., 2006). Altogether, our findings suggest that Imp 


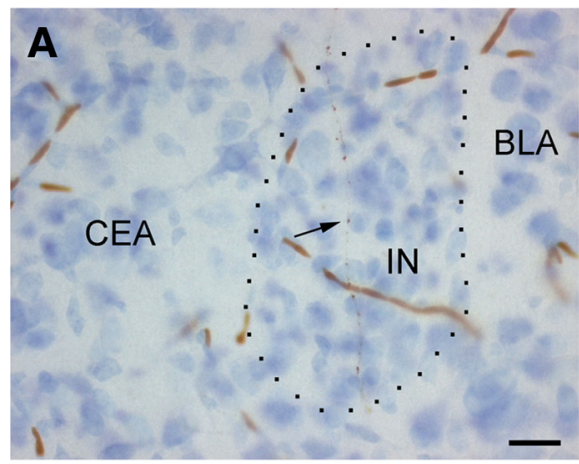

C1

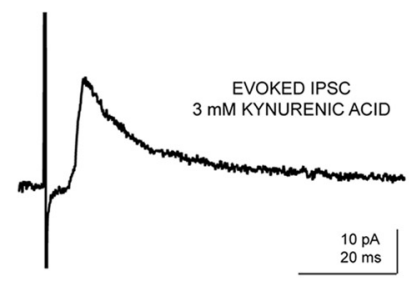

B1

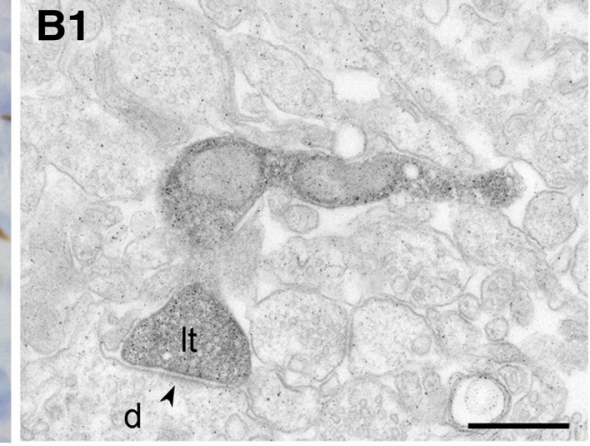

C2

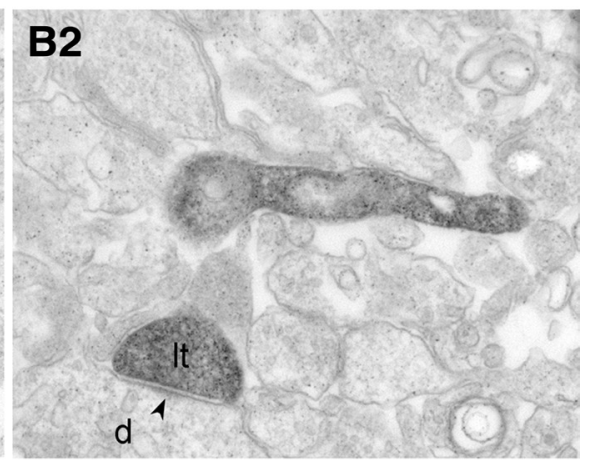

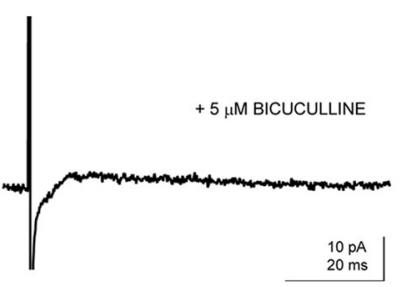
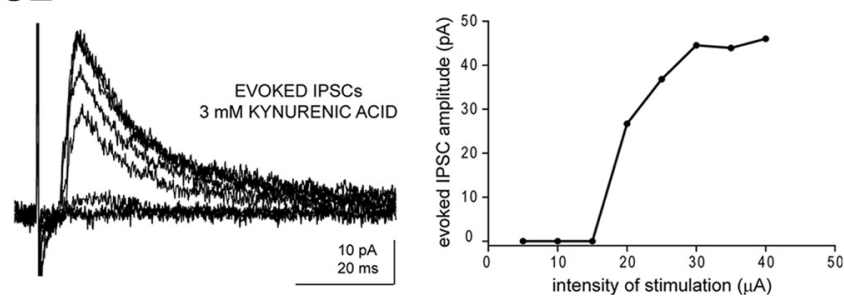

Figure 5. Direct inhibitory connectivity between Imp and IN. A, Light micrograph of IN containing a portion of a biocytin-filled axon (arrow) originated from a MCp-Imp neuron. B1, B2, Electron micrographs of serial sections of a biocytin-labeled axon terminal making a symmetric synapse (arrowhead) with a small dendritic shaft in the IN. C1, Representative IPSCS elicited in the IN during extracellular stimulation in the Imp (trace on the left). The minimal stimulation intensity producing a detectable response in the two positive experiments was 20 and $50 \mu \mathrm{A}$. In the two positive experiments, the IPSCs rise time was 2.1 and $1.2 \mathrm{~ms}$, peak amplitude was 10 and $26 \mathrm{pA}$, decay time constant was 15.7 and $10.2 \mathrm{~ms}$, and latency was 6 and $6.1 \mathrm{~ms}$, respectively. The response was mediated by $\mathrm{GABA}_{A}$ receptors, because it was abolished by $5 \mu$ m bicuculline (trace on the right). Each trace represents the average of 10 sweeps. The IPSCs were evoked at a holding potential of -65 $\mathrm{mV}$. C2, The left panel shows IPSCs evoked in the same cell at increasing stimulation intensities, within the range of 5- $40 \mu \mathrm{A}$. In the right, the input- output curve shows the relation between the intensity of stimulation used and the peak amplitude of the IPSCs. Each point of the graph represents the average value of three sweeps. Note the presence of failures elicited by lower stimulation intensities and the presence of a plateau for higher stimulation intensities. $d$, Dendrite; It, labeled terminal. Scale bars: $A, 50 \mu \mathrm{m} ; \boldsymbol{B}, 500 \mathrm{~nm}$.

neurons differ from CEc neurons in several important morphological and physiological features, therefore dispelling potential reservations of a misclassification.

Full reconstruction by camera lucida of the ITC neurons, for which extensive axonal trees were recovered $(n=53)$, was performed to thoroughly examine the pattern of their axonal projections. A substantial heterogeneity was revealed with many neurons $(n=20)$ projecting their axons along the intermediate capsule in which they often gave rise to two branches, one innervating the IN and the other turning more medially toward the medial amygdaloid nucleus. The axonal projection of other cells $(n=8)$ ran along the dorsomedial border of the CEA toward the internal capsule and reached the AL, in which numerous varicosities and terminal branchlets could be observed. In contrast, many other Imp neurons had axonal ramifications predominantly within the $\operatorname{CEc}(n=16)$ with some collaterals reaching the $\mathrm{CEm}(n=5)$. Some neurons were also observed to send axonal branches in the intra-amygdaloid division of the bed nucleus of the stria terminalis $(n=2)$, within the BLA $(n=6)$, into the interstitial nucleus of the posterior limb of the anterior commissure $(n=5)$, or even coursing through the striatum. Nearly every ITC neuron possessed dense axonal ramifications within the Imp/Iap.

\section{The Imp contains three distinct neuronal classes differing in their axonal projections}

For each reconstructed Imp/Iap neuron, we quantified the respective axonal length in different intra- and extra-amygdaloid nuclei/regions. To assess whether ITC neurons can be objectively divided into well-defined subpopulations based on their axonal pattern and/or electrophysiological responses, we then performed exploratory correlation analyses followed by unsuper- vised clustering. The reliability of the unsupervised methods was assessed by cross-validation and bootstrap resampling. Two ITC neurons were excluded from the cluster analysis because the slice did not contain the CEm. The cluster analysis identified three main Imp/Iap subpopulations (Fig. 4A; Table 4), which we termed, based on the predominant axonal arborizations, as medial capsular-projecting (MCp), sublenticular-projecting (SLp), and CEA-projecting (Cp) neurons. In particular, MCp-Imp neurons $(n=17)$ densely innervated other cells within the same cluster and had a major axonal branch directed ventrally along the main axis of the intermediate capsule to reach the IN (Fig. $4 B$ ). Sixteen cells were classified as SLp-Imp neurons, eight of which gave rise to a primary axonal branch traveling along the dorsal border of the CEA to reach the AL (Fig. 4C). Cp-Imp neurons $(n=18)$ were characterized by their rich innervation of the CEc/l and in some cases of the CEm (Fig. 4D). As summarized in Table 5, neurons in the three groups did not display significant differences in their active and passive membrane electrophysiological responses, apart from the membrane $\tau$ between $\mathrm{MCp}-$ Imp and Cp-Imp (ANOVA, post hoc Bonferroni's test, $p<0.01$ ).

\section{Intrinsic connectivity between Imp and IN}

We then set out to determine whether MCp-Imp neurons are functionally connected with and might exert an inhibitory influence on the IN. At first, we analyzed by serial sectioning-electron microscopy whether axon terminals of biocytin-filled MCp-Imp neurons form synaptic contacts within the IN. Twelve filled boutons, of the 24 examined, were found to establish symmetric synapses with dendritic profiles of IN neurons (Fig. $5 A, B$ ). For the other terminals, no detectable active zone could be identified. We then performed a series of in vitro electrophysiological experiments in which a monopolar electrode was placed in the inter- 

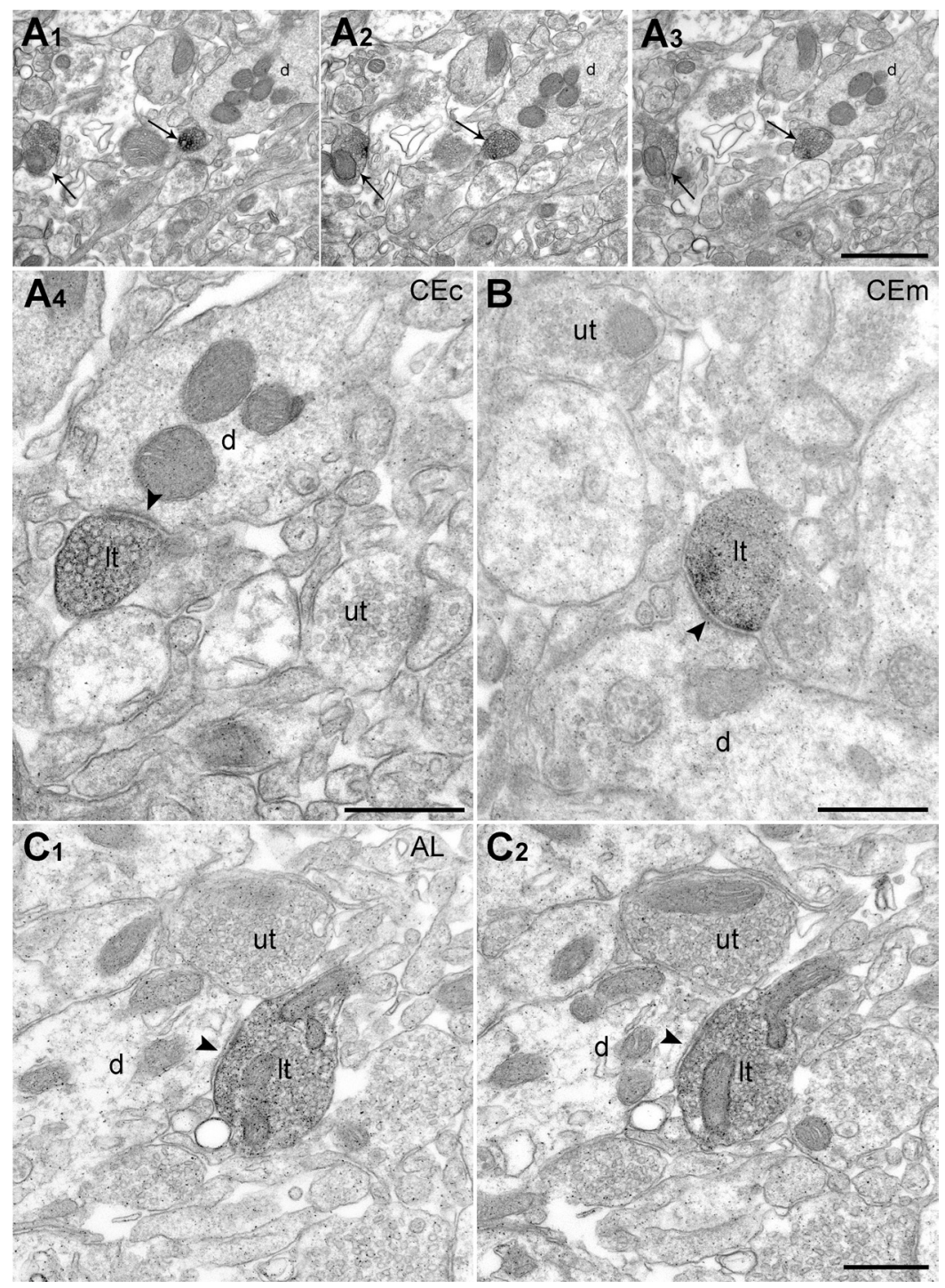

Figure 6. C $\quad$-Imp and SLp-Imp neurons establish inhibitory type II synapses on their target neurons. A1-A3, Micrographs of serial ultrathin sections for electron microscopy showing two labeled axon terminals (arrows) in the CEc. A4, Larger magnification of one of these boutons making a symmetric synapse (arrowhead) with a dendritic shaft. $\boldsymbol{B}$, Symmetric synapse between a labeled axonal terminal of a $\mathrm{C} p$-Imp neuron and a dendrite of a CEm neuron. $C$, Serial sections of a biocytin-labeled axon terminal of an SLP-Imp neuron in the AL. d, Dendrite; It, labeled terminal; ut, unlabeled terminal. Scale bars: A1-A3, $1 \mu \mathrm{m} ; \boldsymbol{A 4 - C ,} 500 \mathrm{~nm}$.

lyzed, nine established synapses with small-diameter dendrites (Fig. 6A) and three with somata. In the CEm, a clear synapse could be detected for only eight terminals of 25 and exclusively on dendritic shafts (Fig. 6B), which would indicate a more efficient inhibition of $\mathrm{CEC}$ then CEm neurons. In the AL $(n=16)$, the postsynaptic targets of SLp-Imp neurons were both somata $(n=3)$ and dendrites $(n=5)$ (Fig. 6C).

We have observed that several large neurons surrounding the ITC clusters displayed IR for the calcium binding proteins parvalbumin and calbindin or the neurotransmitter receptors neurokinin 1 and metabotropic glutamate $1 \alpha(\operatorname{mGlu} 1 \alpha)$. In particular, neurons immunolabeled for the $\mathrm{mGlu} 1 \alpha$ receptor showed very large somata and long and thick primary dendrites that encircled all ITC clusters (Fig. $7 A$ ). To detect whether cells expressing the above markers could represent local postsynaptic targets of medium-sized ITC neurons, double-fluorescence immunolabeling was performed combining Cy3conjugated streptavidin, to reveal the filled axon, with specific antibodies for these markers, before processing the recorded sections for electron microscopy. Putative synaptic contacts were observed only between filled axons of two MCpImp neurons and mGlul $\alpha$ receptorimmunopositive dendrites (Fig. $7 B, C$ ). For one of the recorded neurons, we then confirmed at the ultrastructural level that the filled axon indeed formed a symmetric synapse with an mGlul $\alpha$ receptorimmunolabeled dendritic shaft (Fig. 7D). To establish whether these mGlul $\alpha$ receptor-expressing neurons use GABA as neurotransmitter, we examined in GAD65-GFP mice the coexpression of GFP with $\mathrm{mGlu} 1 \alpha$ receptor (Fig. $7 E$ ) and performed double-immunofluorescence

mediate capsule, and recordings were performed in the IN (anatomically confirmed after the electrophysiological experiments), in the presence of $3 \mathrm{~mm}$ kynurenic acid to block excitatory transmission. Functional monosynaptic connectivity was detected in two of six cells, from six different slices. The evoked IPSCs were mediated through $\mathrm{GABA}_{\mathrm{A}}$ receptors (Fig. $5 C_{1}$ ), because they were completely and reversibly abolished by the $\mathrm{GABA}_{\mathrm{A}}$ receptor antagonist bicuculline $(5 \mu \mathrm{M})$. Different stimulation intensities were used to generate an input-output curve of IPSCs (Fig. $5 C_{2}$ ). These results provide firm functional evidence for a direct intrinsic inhibitory control of a subpopulation of Imp neurons over the IN.

\section{Postsynaptic targets of Imp neurons}

Next, we examined further the postsynaptic targets of biocytinfilled Imp/Iap axon terminals in the CEc, CEm, and AL. As expected, all the synapses established by filled boutons were symmetric. In CEc, of 12 axon terminals of MCp neurons ana- experiments for GABA and mGlul $\alpha$ receptors (Fig. $7 F$ ). Both approaches indicate that these neurons do not possess GABAergic markers in their soma, in agreement with previous studies on large ITC neurons (Nitecka and Ben-Ari, 1987; McDonald and Augustine, 1993; Paré and Smith, 1994).

\section{Different fear states induce the activation of distinct ITC clusters}

The direct inhibitory control of the Imp onto the IN would indicate a reverse pattern of activation of the two clusters under fear states that may differentially engage them. To test this hypothesis, we compared the expression of the immediate early gene Zif268 in coronal slices of the amygdala obtained from mice that were previously subjected to fear conditioning $(n=6)$ versus mice that were fear conditioned and trained on extinction the following day $(n=6)$. An additional group of mice $(n=4)$, which did not receive the US during conditioning, served as control. During fear conditioning, the fear expression and fear extinction groups 


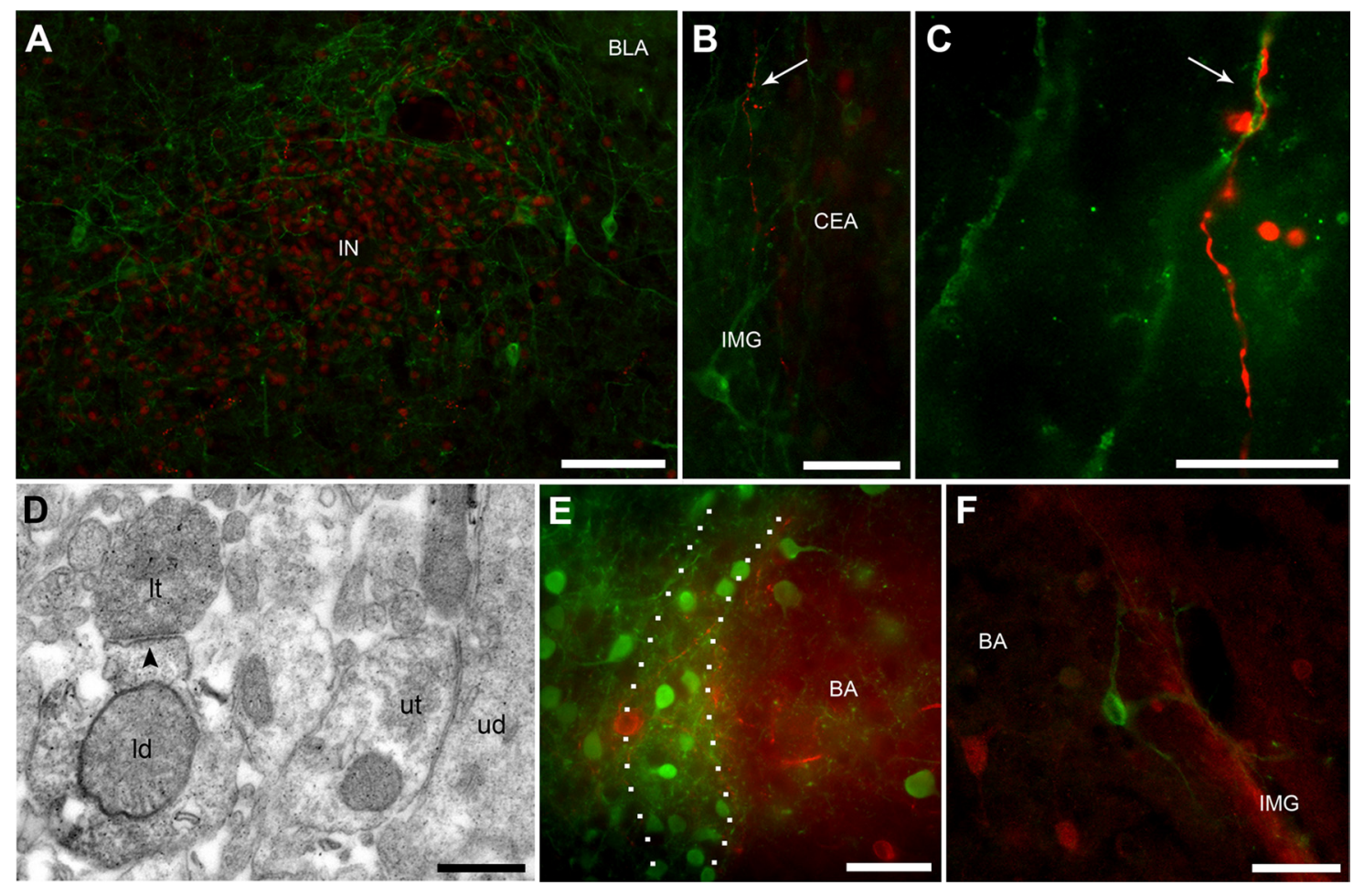

Figure 7. $\mathrm{mGlu1} \alpha$ receptor-immunopositive cells encircle ITC clusters and are targeted by MCp-Imp neurons. A, Double-immunofluorescence micrograph depicting IN clustered neurons immunolabeled for FoxP2 (in red) encircled by the soma and dendrites of large neurons immunolabeled for mGlu1 $\alpha$ receptor (in green). $\boldsymbol{B}, \boldsymbol{C}$, Low-power ( $\boldsymbol{B})$ and high-power (C) micrograph of the filled axon (in red) of a MCp-Imp recorded neuron potentially forming a synaptic contact (arrow) onto a mGlu $1 \alpha$ receptor-immunopositive dendrite (in green) within the intermediate capsule. $D$, Pre-embedding immunoelectron microscopy confirmed that the observed contact is indeed a symmetric synapse (arrowhead). In the ITCs, the soma of neurons containing mGlu1 $\alpha$ receptors do not express GABA as revealed by the lack of colabeling between $\mathrm{mGlu} 1 \alpha$ receptor (in red) and GFP (in green) in GAD65-GFP transgenic mice (E) or between mGlu1 $\alpha$ receptor (in green) and GABA (in red) $(\boldsymbol{F})$. Id, Labeled dendrite; It, labeled terminal. Scale bars: $\boldsymbol{A}, 100 \mu \mathrm{m} ; \boldsymbol{B}, 50 \mu \mathrm{m} ; \boldsymbol{C}, 15 \mu \mathrm{m} ; \boldsymbol{D}, 500 \mathrm{~nm} ; \boldsymbol{E}, \boldsymbol{F}, 50 \mu \mathrm{m}$.

showed a significantly higher freezing to the CS during the third pairing between the CS and US compared with the control group (ANOVA, $F_{(4,26)}=17.97, p<0.001$; Bonferroni's test, $p<0.05$ ), which displayed negligible freezing $(<5 \%)$. No difference in freezing to the CS was observed between fear expression and fear extinction groups during CS-US pairings (Fig. $8 \mathrm{~A}$ ). Extinction training produced a significant reduction in freezing responses $\left(\right.$ ANOVA, $\left.F_{(14,70)}=20.44, p<0.001\right)$ after the sixth presentation (ANOVA, Bonferroni's test, $p<0.05$ ). Pre-CS values remained very low in all groups $(<3 \%)$, which demonstrated the high discrimination of context B versus context A. Fear-related CS exposure enhanced Zif268 expression only in the Imp (ANOVA, $F_{(2,13)}=8.01$, Bonferroni's test, $\left.p<0.01\right)$, whereas after fear extinction both the Imp (Bonferroni's test, $p<0.01$ ) and IN (ANOVA, $F_{(2,13)}=11.62$, Bonferroni's test, $\left.p<0.05\right)$ showed higher number of Zif268-expressing neurons compared with the unconditioned control group (Fig. $8 B-D$ ). In another set of experiments, we then analyzed whether the retrieval of extinction also differently recruits these ITC clusters. As expected, a significant effect of CS on freezing were observed in fear conditioned mice $(n=6)$, which displayed increased freezing during conditioning (ANOVA, $\left.F_{(4,20)}=66.90, p<0.001\right)$ and reduction of freezing during extinction training session (ANOVA, $F_{(14,70)}=$ 45.94, $p<0.001$ ). In comparison, no significant effects of CS were observed during conditioning (ANOVA, $p=0.999$ ) or extinction training (ANOVA, $p=0.999$ ) in unconditioned mice (CS-only) $(n=4)$. Extinction retrieval in conditioned mice revealed a significantly lower fear expression compared with fear recall (Wilcoxon's test, $p<0.05$ ) (Fig. $8 E$ ). Pre-CS values remained very low in all groups $(<5 \%$ freezing in conditioned and unconditioned mice). The number of Zif268-positive cells was significantly increased in the IN after extinction retrieval (ANOVA, $F_{(1,8)}=50.492, p<0.001$ ), whereas no changes were observed in the Imp compared with the unconditioned group (ANOVA, $p=0.854$ ) (Fig. $8 F, G)$.

\section{Discussion}

In the present work, we provide evidence for the differential recruitment in fear expression and retrieval of extinction of two distinct ITC clusters located within the intermediate capsule, namely the Imp and IN. We also show that this differential activation, measured as Zif268 expression, is likely attributable to a direct regulatory control of the Imp over the IN through GABAergic monosynaptic connections. Through detailed structural analysis of Imp neurons, we demonstrate the existence of three distinct cell classes characterized by axonal projections targeting different brain areas. Indeed, one of these neuronal subtypes, termed MCp-Imp, specifically and directly innervates the IN. Furthermore, we found that MCpImp neurons establish a novel intra-ITC connection with large neurons expressing $\mathrm{mGlu} 1 \alpha$ receptors; this network resembles the circuit between striatal and type II pallidal neurons within the basal ganglia.

\section{Heterogeneity and classification of Imp neurons}

By combining whole-cell patch-clamp recording and biocytin labeling with full anatomical reconstruction and unsupervised cluster analysis, we were able to demonstrate that the Imp/Iap clusters are composed of at least three distinct neuronal subtypes with highly divergent axonal patterns, as shown schematically in 
A

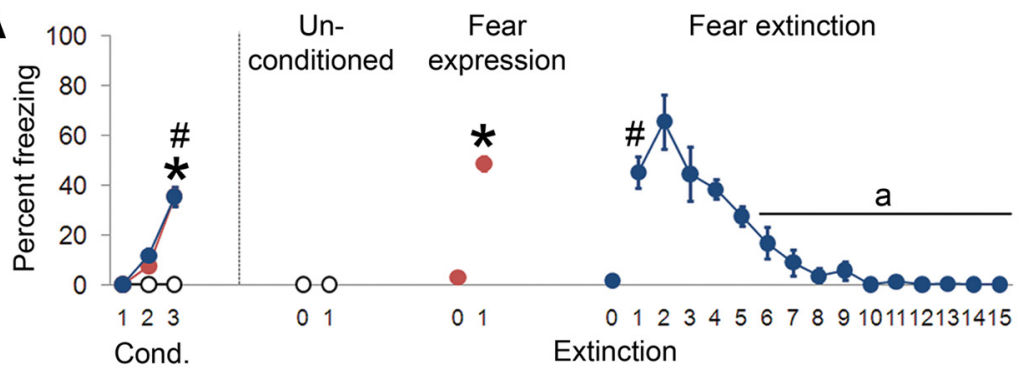

B

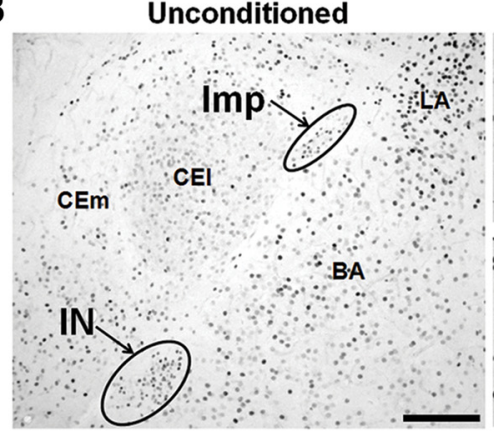

C

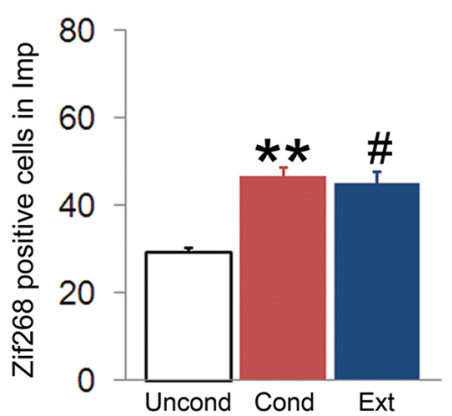

E

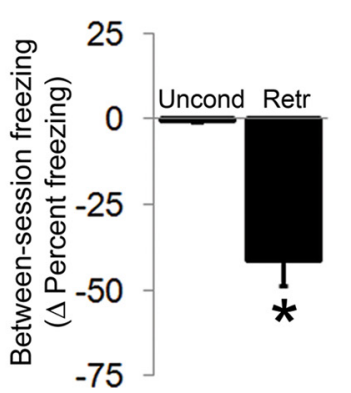

Fear expression Fear extinction

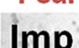

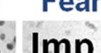
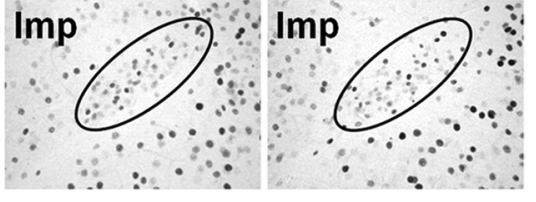

IN
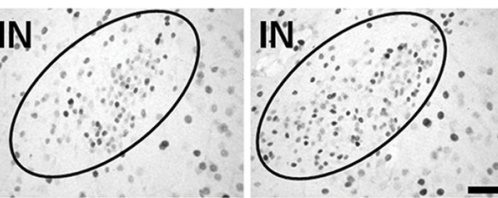

D

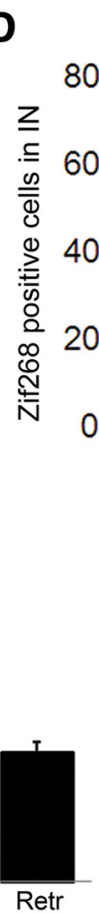

$\S$

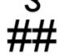

F

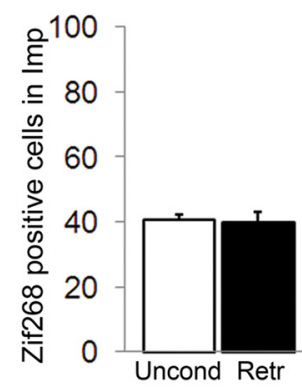

G

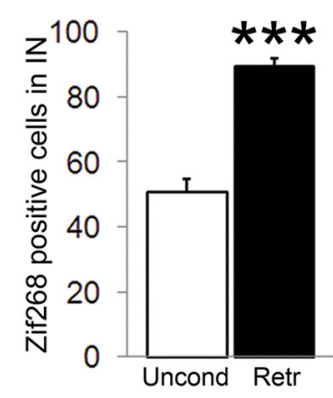

Figure 8. Differential activation of Imp and IN during fear acquisition, extinction, and extinction retrieval. $\boldsymbol{A}$, Percentage of freezing during each presentation of the CS for the conditioned (CS-US paired) fear expression (red circles), fear extinction (blue circles), and unconditioned (CS-only) control (open black circles) groups. $\boldsymbol{B}$, Representative photomicrographs of Imp and IN expressing Zif268 in unconditioned control, fear expression, and fear extinction groups in different fear states. $\boldsymbol{C}$, In the Imp, both the fear expression (red histogram) and fear extinction (blue histogram) groups showed a greater number of Zif268-positive cells relative to unconditioned mice (white histogram). $\boldsymbol{D}$, In the IN, the fear extinction group showed a greater increase in the number of Zif268-positive cells relative to unconditioned and fear expression groups. $\boldsymbol{E}$, Between-session extinction freezing changes (measured as fear expression during extinction retrieval minus fear expression during fear recall) in conditioned (black histogram) and unconditioned (white histogram) groups. $\boldsymbol{F}$, No difference in the number of Zif268-positive cells was observed in the Imp between conditioned and unconditioned mice during retrieval of extinction. $\mathbf{G}$, The fear extinction group displayed an increased number of Zif268-positive cells in the IN relative to unconditioned mice during retrieval of extinction. cond., Fear expression; ext., fear extinction; retr., extinction retrieval; uncond., unconditioned. ${ }^{*} p<0.05,{ }^{* *} p<0.01$, fear expression versus unconditioned, ${ }^{\#} p<0.05,{ }^{\# \#} p<0.01$, fear extinction versus unconditioned, ${ }^{\S} p<0.05$ fear extinction versus fear expression, ${ }^{a} p<0.05$ within-group CS presentation versus first CS presentation. Scale bars: $\boldsymbol{B}$, left, $100 \mu \mathrm{m} ; \boldsymbol{B}$, middle and right, $40 \mu \mathrm{m}$.

Figure 9. Our polythetic classification of Imp neurons thus leads to the emergence of a much more complex picture for ITC networks. We also demonstrate that Imp neurons differ both anatomically and physiologically from CEc neurons, emphasizing the distinctiveness of these cells from other neurons of the amygdala. Our findings corroborate the view that the ITCs represent, at least cytoarchitectonically, a ventral extension of the basal ganglia (Millhouse, 1986). Although the ITCs are operationally independent from the basal ganglia, they appear to share the same functional units and modular organization, e.g., the medium-sized spiny ITC neurons equating those of the striatum and the large neurons with those of the globus pallidus, because they also express $\mathrm{mGlu} 1 \alpha$ receptors (Ferraguti et al., 2008). Striatal and ITC neurons may also have a common developmental origin as indeed suggested by the similar expression of transcription factors characterizing the lateral ganglionic eminence (Kaoru et al., 2010; Waclaw et al., 2010), from which they both migrate.

SLp-Imp neurons project outside the amygdala to cholinergic forebrain areas The newly identified SLp-Imp neurons send projections to the AL in which their axons made, along their course, en passant synapses and also emitted short terminal branchlets contacting the somata and dendrites of neurons of the interstitial nucleus of the AL. It is plausible that these axons further extend to other areas, most likely to the cholinergic basal forebrain (Paré and Smith, 1994), although this could not be proven because of the limited thickness of acute slices. However, the interstitial nucleus of the AL can be considered part of the basal forebrain, the primary source of cholinergic inputs to the basal nucleus of amygdala (BA) (Carlsen and Heimer, 1986). Similarly to the nucleus basalis magnocellularis, it is composed of cholinergic and GABAergic neurons. This projection might reduce the cholinergic tone in the BA and cortex and contribute to the inhibition of fear memories retrieval and fear expression (Myers and Davis, 2002) via a different pathway from those to the CEA and IN.

MCp-Imp neurons selectively target the IN and mediate a novel intra-ITC GABAergic connection

MCp-Imp cells send a main axonal branch to the IN and form symmetric synapses with dendrites of neurons in this cluster. There- 

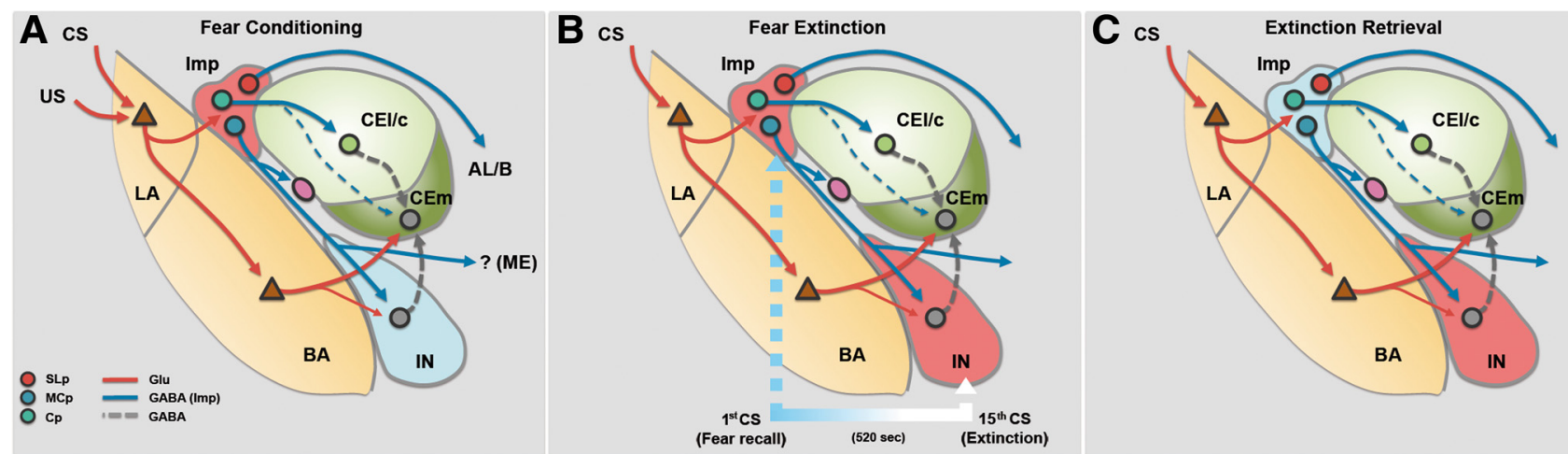

Figure 9. ITC neurons mediate multiple inhibitory circuits in the amygdala during fear conditioning and extinction. $A$, Three distinct classes of ITC neurons have been observed in the Imp: (1) MCp-Imp cells (blue circle) directly inhibiting neurons of the IN and large mGlu1 $\alpha$-IR ITC neurons (purple circle) and perhaps sending an axonal branch to the ME; (2) Cp-Imp neurons ( $g r e e n$ circle) projecting to the CEA; and (3) SLp-Imp cells (red circle) targeting the AL or the nucleus basalis of Meinert (B). During fear conditioning, the selective activation (measured as increased Zif268 expression and schematically shown here as the cluster colored in red) of the Imp by the lateral nucleus of amygdala after CS-US pairings, triggers feedforward inhibition in the IN (shown in light blue) and CEc/l. This leads to the disinhibition of CEm output neurons. B, During fear extinction training, the initial presentation of the CS (light blue dashed arrow) produces fear recall and an ensuing activation of the Imp. Conversely, the persistent presentation of the CS alone (white arrow) leads to the activation of the IN. Therefore, both clusters appear activated because the temporal window of Zif268 activation ( $>1 \mathrm{~h}$ ) exceeds the time gap (520 s) between the first and the last (15th) CS exposure. C, During extinction retrieval, only the IN is active, which in turn inhibits the CEm and fear expression. Imp-CEm connections have been shown recently (Mańko et al., 2011). Dashed lines represent pathways that are yet not fully characterized. LA, Lateral nucleus of amygdala; ME, medial nucleus.

fore, our data provide firm functional evidence for a direct intrinsic inhibitory control of MCp-Imp neurons over the IN, and this inhibition itself should be able to prevent activity in the targeted cells within the IN. The result that only in $\sim 30 \%$ of the cases we could elicit IPSCs in the IN after stimulation in the Imp is consistent with the ratio of MCp-Imp neurons ( $\sim 33 \%)$ and the rather sparse nature of their axonal branches in the IN. Our data further revealed that MCp-Imp neurons establish a novel intra-ITC GABAergic connection with large mGlul $\alpha$ receptor-containing neurons, which are found along the edge of the densely packed clusters of medium spiny ITC neurons and are to be considered ITC neurons themselves. Previous Golgi studies noted the presence of these large neurons (Millhouse, 1986) but could not establish their participation to a specific network.

\section{Cp-Imp neurons provide a major GABAergic projection to the CEA}

Among the three main Imp/Iap subpopulations, the Cp-Imp neurons provide the densest projection to the CEA, in concordance with previous tract tracing studies in the cat (Paré and Smith, 1993, 1994) and thus integrate them in the feedforward disinhibitory circuit targeting the CEm. However, our data indicate that $\mathrm{Cp}$-Imp cells primarily target $\mathrm{CEc} / \mathrm{l}$ rather than $\mathrm{CEm}$ neurons, although this could reflect a limited recovery of axonal branches reaching the CEm in acute slices. CEm output is tightly controlled by local inhibition from CEc/l (Cassell et al., 1999). We can thus postulate, although by oversimplification, that $\mathrm{Cp}-$ Imp neurons inhibit $\mathrm{CEc} / \mathrm{l}$, resulting in disinhibition of CEm (Fig. 9). Because ITC cells have a high firing rate with limited spike frequency accommodation (Royer et al., 2000; Marowsky et al., 2005; Geracitano et al., 2007), e.g., compared with CEc neurons, they are likely to exert a strong tonic inhibitory influence on their recipient neurons. However, the CEc/l consists of a heterogeneous population of local inhibitory neurons with distinct inputs and outputs and, as a result, with distinct roles in shaping CEm output activity. Therefore, additional characterization of the target/s of Cp-Imp neurons in the CEA is warranted.

\section{Distinct role of ITC clusters in different fear states}

The recruitment of ITC neurons by BLA and infralimbic cortex (IL) was proposed to account for the inhibition of CEm neurons and hence of fear expression after extinction training (Milad and Quirk, 2002; Burgos-Robles et al., 2007; Jüngling et al., 2008; Sotres-Bayon et al., 2008; Amano et al., 2010). Ablation of ITC neurons within the intermediate capsule after extinction training caused a marked deficit in extinction retrieval (Likhtik et al., 2008), providing decisive evidence for the involvement of these neurons for the expression of extinction. However, the critical issue of how distinct ITC clusters in the intermediate capsule contribute to accomplish a synaptic inhibition of CEm neurons remained unresolved. Here, we found that Imp and IN are differentially activated during different fear states and that the IN, active during extinction and extinction retrieval, is under direct inhibitory control from the Imp through projections from MCpImp neurons, as schematically shown in the diagrams in Figure 9. Our findings are consistent with the postulated (Paré et al., 2004; Pape and Paré, 2010) hierarchical and unidirectional control between ITC clusters and also indicate that they have a precise functional specialization in fear learning.

The concurrent activation of both the Imp and IN after extinction acquisition would appear at odds with a differential recruitment of these clusters in diverse fear states. This may be explained by the relatively short interval between the representation of the first CS, which triggers once more the conditioned response, and the completion of the extinction protocol. Because of this narrow temporal window, the induction of Zif268 expression could be attributable to either fear recall or extinction learning (Fig. 9). Because extinction recall did not engage the Imp, it can be surmised that its activation associates to fear expression and not extinction. However, the role of the Imp may not be confined only to fear expression. In fact, SLp-Imp neurons through inhibition of the cholinergic basal forebrain may switch the fear response from freezing to risk assessment and exploration (Gozzi et al., 2010). Likewise, Cp-Imp neurons may provide an important inhibitory drive onto $\mathrm{CEc} / \mathrm{l}$ neurons and in turn affect the output of CEm neurons. How the different Imp neurons might influence behavioral transitions requires additional experimental clarification, although the temporal sequence and source of activation of these neurons might be critical factors (Royer et al., 1999, 2000; Royer and Paré, 2002). In this respect, besides a potential divergence in the efferent projections of the 
Imp and IN (Royer et al., 1999; Mánko et al., 2011), these two clusters most likely integrate different inputs. In fact, lateral nucleus of amygdala and BA send strong topographically organized inputs to the Imp (Pitkanen and Amaral, 1994; Royer et al., 1999; Jüngling et al., 2008) and IN (Royer et al., 1999), respectively. Likewise, areas outside the amygdala, such as the IL (McDonald et al., 1996; Pinto and Sesack, 2008), provide different input densities to these clusters. Here, we also observed that the Imp receives denser TH-positive innervation compared with the IN, at least in its intra-amygdala component.

It remains to be elucidated how distinct ITCs cooperate to subside fear with other neuronal networks engaged by extinction-mediated mechanisms (Herry et al., 2008). Particularly interesting in this respect is the recent finding that extinction-related enhancement in the efficacy of excitatory synaptic transmission at BLA-ITC synapses is dependent on IL activity during extinction training (Amano et al., 2010). In fact, it is attractive to speculate that changes in synaptic activity at discrete inputs to distinct ITC neurons/clusters (Royer and Paré, 2002; Jüngling et al., 2008) have a dual function to trigger either inhibition or disinhibition of downstream ITCs depending on the behavioral state.

\section{Conclusions}

The potential to dynamically shape incoming and outgoing information to and from the amygdala through a variety of pathways and control mechanisms, puts ITCs in an ideal position to modulate fear expression and extinction, and identifies them as a prime target for pharmacological manipulation for the treatment of anxiety disorders.

\section{References}

Airaksinen MS, Eilers J, Garaschuk O, Thoenen K, Konnerth A, Meyer M (1997) Ataxia and altered dendritic calcium signaling in mice carrying a targeted null mutation of the calbindin D28 gene. Proc Nati Acad Sci U S A 94:1488-1493.

Alheid G, de Olmos J, Beltramino C (1995) Amygdala and extended amygdala. In: The rat nervous system (Paxinos G, ed), pp 495-578. Sydney: Academic.

Amano T, Unal CT, Paré D (2010) Synaptic correlates of fear extinction in the amygdala. Nat Neurosci 13:489-494.

Amaral DG, Price JL (1984) Amygdalo-cortical projections in the monkey (Macaca fascicularis). J Comp Neurol 230:465-496.

Ausubel FM (1992) Short protocols in molecular biology. New York: Wiley.

Blanchard RJ, Blanchard DC (1969) Passive and active reactions to feareliciting stimuli. J Comp Physiol Psychol 68:129-135.

Burgos-Robles A, Vidal-Gonzalez I, Santini E, Quirk GJ (2007) Consolidation of fear extinction requires NMDA receptor-dependent bursting in the ventromedial prefrontal cortex. Neuron 53:871-880.

Campbell P, Reep RL, Stoll ML, Ophir AG, Phelps SM (2009) Conservation and diversity of Foxp2 expression in muroid rodents: functional implications. J Comp Neurol 512:84-100.

Carlsen J, Heimer L (1986) A correlated light and electron microscopic immunocytochemical study of cholinergic terminals and neurons in the rat amygdaloid body with special emphasis on the basolateral amygdaloid nucleus. J Comp Neurol 244:121-136.

Cassell MD, Freedman LJ, Shi C (1999) The intrinsic organization of the central extended amygdala. Ann N Y Acad Sci 877:217-241.

Chieng BC, Christie MJ, Osborne PB (2006) Characterization of neurons in the rat central nucleus of the amygdala: cellular physiology, morphology, and opioid sensitivity. J Comp Neurol 497:910-927.

Conn PM (1999) Methods in enzymology. San Diego: Academic.

Davis M, Ressler K, Rothbaum BO, Richardson R (2006) Effects of D-cycloserine on extinction: translation from preclinical to clinical work. Biol Psychiatry 60:369-375.

de Olmos J (1990) The amygdala. In: The human nervous system (Paxinos G, ed), pp 583-710. New York: Academic.

Ehrlich I, Humeau Y, Grenier F, Ciocchi S, Herry C, Lüthi A (2009)
Amygdala inhibitory circuits and the control of fear memory. Neuron 62:757-771.

Enard W, Gehre S, Hammerschmidt K, Hölter SM, Blass T, Somel M, Brückner MK, Schreiweis C, Winter C, Sohr R, Becker L, Wiebe V, Nickel B, Giger T, Müller U, Groszer M, Adler T, Aguilar A, Bolle I, Calzada-Wack J, et al. (2009) A humanized version of Foxp2 affects cortico-basal ganglia circuits in mice. Cell 137:961-971.

Ferraguti F, Cobden P, Pollard M, Cope D, Shigemoto R, Watanabe M, Somogyi P (2004) Immunolocalization of metabotropic glutamate receptor lalpha (mGluRlalpha) in distinct classes of interneuron in the CA1 region of the rat hippocampus. Hippocampus 14:193-215.

Ferraguti F, Crepaldi L, Nicoletti F (2008) Metabotropic glutamate 1 receptor: current concepts and perspectives. Pharmacol Rev 60:536-581.

Fuxe K, Jacobsen KX, Höistad M, Tinner B, Jansson A, Staines WA, Agnati LF (2003) The dopamine D1 receptor-rich main and paracapsular intercalated nerve cell groups of the rat amygdala: relationship to the dopamine innervation. Neuroscience 119:733-746.

Geracitano R, Kaufmann WA, Szabo G, Ferraguti F, Capogna M (2007) Synaptic heterogeneity between mouse paracapsular intercalated neurons of the amygdala. J Physiol 585:117-134.

Gozzi A, Jain A, Giovanelli A, Bertollini C, Crestan V, Schwarz AJ, Tsetsenis T, Ragozzino D, Gross CT, Bifone A (2010) A neural switch for active and passive fear. Neuron 67:656-666.

Hefner K, Whittle N, Juhasz J, Norcross M, Karlsson RM, Saksida LM, Bussey TJ, Singewald N, Holmes A (2008) Impaired fear extinction learning and cortico-amygdala circuit abnormalities in a common genetic mouse strain. J Neurosci 28:8074-8085.

Herry C, Ciocchi S, Senn V, Demmou L, Müller C, Lüthi A (2008) Switching on and off fear by distinct neuronal circuits. Nature 454:600-606.

Herry C, Ferraguti F, Singewald N, Letzkus JJ, Ehrlich I, Lüthi A (2010) Neuronal circuits of fear extinction. Eur J Neurosci 31:599-612.

Holmes A, Quirk GJ (2010) Pharmacological facilitation of fear extinction and the search for adjunct treatments for anxiety disorders-the case of yohimbine. Trends Pharmacol Sci 31:2-7.

Jüngling K, Seidenbecher T, Sosulina L, Lesting J, Sangha S, Clark SD, Okamura N, Duangdao DM, Xu YL, Reinscheid RK, Pape HC (2008) Neuropeptide S-mediated control of fear expression and extinction: role of intercalated GABAergic neurons in the amygdala. Neuron 59:298-310.

Kägi U, Berchtold MW, Heizmann CW (1987) $\mathrm{Ca}^{2+}$-binding parvalbumin in rat testis. Characterization, localization, and expression during development. J Biol Chem 262:7314-7320.

Kaoru T, Liu FC, Ishida M, Oishi T, Hayashi M, Kitagawa M, Shimoda K, Takahashi H (2010) Molecular characterization of the intercalated cell masses of the amygdala: implications for the relationship with the striatum. Neuroscience 166:220-230.

Kaufmann WA, Ferraguti F, Fukazawa Y, Kasugai Y, Shigemoto R, Laake P, Sexton JA, Ruth P, Wietzorrek G, Knaus HG, Storm JF, Ottersen OP (2009) Large-conductance calcium-activated potassium channels in Purkinje cell plasma membranes are clustered at sites of hypolemmal microdomains. J Comp Neurol 515:215-230.

Keane TM, Marshall AD, Taft CT (2006) Posttraumatic stress disorder: etiology, epidemiology, and treatment outcome. Annu Rev Clin Psychol 2:161-197.

Likhtik E, Popa D, Apergis-Schoute J, Fidacaro GA, Paré D (2008) Amygdala intercalated neurons are required for expression of fear extinction. Nature 454:642-645.

Lode HN, Pertl U, Xiang R, Gaedicke G, Reisfeld RA (2000) Tyrosine hydroxylase-based DNA-vaccination is effective against murine neuroblastoma. Med Pediatr Oncol 35:641-646.

López-Bendito G, Sturgess K, Erdélyi F, Szabó G, Molnár Z, Paulsen O (2004) Preferential origin and layer destination of GAD65-GFP cortical interneurons. Cereb Cortex 14:1122-1133.

Mánko M, Geracitano R, Capogna M (2011) Functional connectivity of the main intercalated nucleus of the amygdala. J Physiol. Advance online publication. Retrieved March 1, 2011. doi:10.1113/jphysiol.2010.201475.

Marowsky A, Fritschy JM, Vogt KE (2004) Functional mapping of GABA A receptor subtypes in the amygdala. Eur J Neurosci 20:1281-1289.

Marowsky A, Yanagawa Y, Obata K, Vogt KE (2005) A specialized subclass of interneurons mediates dopaminergic facilitation of amygdala function. Neuron 48:1025-1037.

Mátyás F, Freund TF, Gulyás AI (2004) Convergence of excitatory and in- 
hibitory inputs onto CCK-containing basket cells in the CA1 area of the rat hippocampus. Eur J Neurosci 19:1243-1256.

McDonald AJ, Augustine JR (1993) Localization of GABA-like immunoreactivity in the monkey amygdala. Neuroscience 52:281-294.

McDonald AJ, Betette RL (2001) Parvalbumin-containing neurons in the rat basolateral amygdala: morphology and co-localization of Calbindin$\mathrm{D}(28 \mathrm{k})$. Neuroscience 102:413-425.

McDonald AJ, Mascagni F, Guo L (1996) Projections of the medial and lateral prefrontal cortices to the amygdala: a Phaseolus vulgaris leucoagglutinin study in the rat. Neuroscience 71:55-75.

Menegola M, Misonou H, Vacher H, Trimmer JS (2008) Dendritic A-type potassium channel subunit expression in CA1 hippocampal interneurons. Neuroscience 154:953-964.

Milad MR, Quirk GJ (2002) Neurons in medial prefrontal cortex signal memory for fear extinction. Nature 420:70-74.

Millhouse OE (1986) The intercalated cells of the amygdala. J Comp Neurol 247:246-271.

Muller JF, Mascagni F, McDonald AJ (2009) Dopaminergic innervation of pyramidal cells in the rat basolateral amygdala. Brain Struct Funct 213:275-288.

Myers KM, Davis M (2002) Behavioral and neural analysis of extinction. Neuron 36:567-584.

Nitecka L, Ben-Ari Y (1987) Distribution of GABA-like immunoreactivity in the rat amygdaloid complex. J Comp Neurol 266:45-55.

Pape HC, Paré D (2010) Plastic synaptic networks of the amygdala for the acquisition, expression, and extinction of conditioned fear. Physiol Rev 90:419-463.

Paré D, Smith Y (1993) The intercalated cell masses project to the central and medial nuclei of the amygdala in cats. Neuroscience 57:1077-1090.

Paré D, Smith Y (1994) GABAergic projection from the intercalated cell masses of the amygdala to the basal forebrain in cats. J Comp Neurol 344:33-49.

Paré D, Quirk GJ, Ledoux JE (2004) New vistas on amygdala networks in conditioned fear. J Neurophysiol 92:1-9.

Paxinos K, Franklin G (2001) The mouse brain in stereotaxic coordinates. San Diego: Academic.

Piggins HD, Samuels RE, Coogan AN, Cutler DJ (2001) Distribution of substance $\mathrm{P}$ and neurokinin-1 receptor immunoreactivity in the suprachiasmatic nuclei and intergeniculate leaflet of hamster, mouse, and rat. J Comp Neurol 438:50-65.

Pinto A, Sesack SR (2008) Ultrastructural analysis of prefrontal cortical inputs to the rat amygdala: spatial relationships to presumed dopamine axons and D1 and D2 receptors. Brain Struct Funct 213:159-175.

Pirker S, Schwarzer C, Czech T, Baumgartner C, Pockberger H, Maier H, Hauer B, Sieghart W, Furtinger S, Sperk G (2003) Increased expression of GABA(A) receptor beta-subunits in the hippocampus of patients with temporal lobe epilepsy. J Neuropathol Exp Neurol 62:820-834.
Pitkänen A, Amaral DG (1994) The distribution of GABAergic cells, fibers, and terminals in the monkey amygdaloid complex: an immunohistochemical and in situ hybridization study. J Neurosci 14:2200-2224.

Prohaska JR, Brokate B (2001) Dietary copper deficiency alters protein levels of rat dopamine beta-monooxygenase and tyrosine monooxygenase. Exp Biol Med (Maywood) 226:199-207.

Quirk GJ, Mueller D (2008) Neural mechanisms of extinction learning and retrieval. Neuropsychopharmacology 33:56-72.

Regad T, Bellodi C, Nicotera P, Salomoni P (2009) The tumor suppressor Pml regulates cell fate in the developing neocortex. Nat Neurosci 12:132-140

Royer S, Paré D (2002) Bidirectional synaptic plasticity in intercalated amygdala neurons and the extinction of conditioned fear responses. Neuroscience 115:455-462.

Royer S, Martina M, Paré D (1999) An inhibitory interface gates impulse traffic between the input and output stations of the amygdala. J Neurosci 19:10575-10583.

Royer S, Martina M, Paré D (2000) Polarized synaptic interactions between intercalated neurons of the amygdala. J Neurophysiol 83:3509-3518.

Sätzler K, Söhl LF, Bollmann JH, Borst JG, Frotscher M, Sakmann B, Lübke JH (2002) Three-dimensional reconstruction of a calyx of Held and its postsynaptic principal neuron in the medial nucleus of the trapezoid body. J Neurosci 22:10567-10579.

Sotres-Bayon F, Corcoran KA, Peters J, Sierra-Mercado D (2008) Neural correlates of individual variability in fear extinction. J Neurosci $28: 12147-12149$

Tanahira C, Higo S, Watanabe K, Tomioka R, Ebihara S, Kaneko T, Tamamaki N (2009) Parvalbumin neurons in the forebrain as revealed by parvalbumin-Cre transgenic mice. Neurosci Res 63:213-223.

Tanaka J, Nakagawa S, Kushiya E, Yamasaki M, Fukaya M, Iwanaga T, Simon MI, Sakimura K, Kano M, Watanabe M (2000) Gq protein alpha subunits Galphaq and Galpha11 are localized at postsynaptic extrajunctional membrane of cerebellar Purkinje cells and hippocampal pyramidal cells. Eur J Neurosci 12:781-792.

Vertes RP, Hoover WB (2008) Projections of the paraventricular and paratenial nuclei of the dorsal midline thalamus in the rat. J Comp Neurol 508:212-237.

von Bohlen und Halbach O, Unsicker K (2002) Morphological alterations in the amygdala and hippocampus of mice during ageing. Eur J Neurosci 16:2434-2440

Waclaw RR, Ehrman LA, Pierani A, Campbell K (2010) Developmental origin of the neuronal subtypes that comprise the amygdalar fear circuit in the mouse. J Neurosci 30:6944-6953.

Whittle N, Hauschild M, Lubec G, Holmes A, Singewald N (2010) Rescue of impaired fear extinction and normalization of cortico-amygdala circuit dysfunction in a genetic mouse model by dietary zinc restriction. J Neurosci 30:13586-13596. 